\title{
Properties of Reactive Al:Ni Compacts Fabricated by Radial Forging of Elemental and Alloy Powders
}

\author{
J. D. Gibbins ${ }^{1 *}$, A. K. Stover ${ }^{1}$, N. M. Krywopusk ${ }^{1}$, K. Woll $^{1,2}$, and T.P. Weihs ${ }^{1}$ \\ ${ }^{1}$ Johns Hopkins University, 3400 N. Charles St., Baltimore, MD, 21218 \\ ${ }^{2}$ Institute for Applied Materials, Karlsruhe Institute of Technology, \\ 76344 Eggenstein-Leopoldshafen, Germany \\ *Corresponding Author Email: jgibbins6@gmail.com \\ *Corresponding Author Phone Number: 443-834-8289
}

\begin{abstract}
We explore rotary swaging of powders into solid compacts as an inexpensive means of producing reactive materials with refined microstructures and improved properties. Rotary swaging is a cold forging process that reduces the diameter of tubes, and in this study the tubes are packed with reactive combinations of elemental and alloy powders. The diameter reductions create a nearly fully dense compact from the powders and also reduce the average reactant spacing through plastic deformation. The extent of diameter reduction controls the microstructural refinement, observed through cross-sectional imaging. We correlate the observed changes in microstructure with reaction properties that are characterized using differential scanning calorimetry (DSC), hot-plate ignition studies, and velocity measurements. Exothermic peaks in DSC scans all shift to lower onset temperatures; hot plate ignition temperatures decrease; and reaction velocities rise as the degree of swaging is increased. We vary the shape of the initial reactants by substituting Ni flakes for Ni powders and find no improvement in microstructure or reaction properties, due to clumping of the Ni flakes during the initial compaction steps. We also vary chemistry by substituting Al-Mg alloy powders for $\mathrm{Al}$ powders and find that the alloy powders yield lower DSC exothermic peak temperatures, lower ignition temperatures, and higher reaction velocities compared to similar compacts with pure $\mathrm{Al}$
\end{abstract}


powders. This combination of results suggests that rotary swaging is an effective technique for producing reactive materials at low cost.

Keywords: Mechanical Processing, Reactive Materials, Differential Scanning Calorimetry, Hot Plate Ignition, Aluminum, Nickel

\section{Introduction}

Exothermic formation reactions that generate intermetallic compounds and heat have been studied extensively [1-8] and can occur in compacts of homogeneous [1-8], composite [928] or core shell particles [29-31], or in layered films [32-40] or foils [41-45]. These reactive materials (RMs) can be fabricated either through a bottom up deposition method or using a topdown mechanical process. Most deposition methods utilize physical vapor deposition (PVD), such as magnetron sputtering, and allow for precise control of the average reactant spacing on a nanometer scale [32-40]. However, such processes are more expensive than mechanical methods due to high capital costs and lower throughput on a per mass basis. Mechanical methods for fabricating RMs include ball-milling [9, 11-19, 21-28], rolling [10, 41-45], and cold isostatic pressing [3]. These methods typically have lower capital costs and higher throughputs but cannot achieve the same microstructural uniformity as PVD methods. However, ball milling is capable of fabricating composite powders with reactant spacing on the scale of 10's of nanometers [9, 11-19, 21-28].

Rotary swaging is an alternative mechanical processing method with low capital costs, inexpensive starting materials, and high throughput. The swaging process works by rapidly compressing a rod or tube through a series of radial reductions [46-49]. The swager itself contains a large flywheel that rotates a roll cage with roller bearings over different interchangeable dies with varying diameters as shown in Figure 1(a). As the roller bearings pass over the dies, the dies rapidly compress against a tube or rod, causing it to condense to the desired outer diameter (OD) as shown in Figure 1(b). Each set of dies introduces a given average strain to the sample, and the number of dies and the strain for each set of dies can be varied. The radial nature of the deformation minimizes fracture within the sample and thus leads to higher materials utilization compared to cold rolling. The large plastic strains imparted by the 
dies act to shear the constituent powders, breaking surface oxides and enhancing bonding between powders. This is important for compacts containing Al powders.

With rotary swaging, one can control the degree of microstructural refinement and hence the reactivity of the resulting powder compacts in multiple ways. One is through the total reduction of the rod's diameter with larger reductions leading to more refinement. A second is through the size of the starting powders with smaller initial powders leading to finer and more reactive as-fabricated microstructures, as seen in earlier powder compacts [7]. A third is through the use of composite particles such as ball-milled, laminate or core-shell powders. Lastly, alloying the elemental particles can also enhance the reactivity of the final compacts. To examine all four factors, we characterize the microstructures and properties of reactive compacts that were swaged from elemental powders ( $\mathrm{Al}$ and $\mathrm{Ni}$ ), alloy powders (Al-Mg), Ni flakes, and laminate powders (Ni:Al), and the effects of swaging reduction, initial particle geometry, composite powders, and reactant chemistry are assessed.

\section{Experimental Procedures}

\subsection{Fabricating Materials}

Five different samples were fabricated using various powder chemistries and geometries as shown in Table 1: a) Al powders and Ni powders (Al:Ni P/P), b) Al powders and Ni flakes (Al:Ni P/F) c) Al-Mg powders and Ni powders (Al-Mg:Ni P/P) d) Al-Mg powders and Ni flake (Al-Mg:Ni P/F) and e) Ni:Al laminate powders (Al:Ni LP). The single phase powders and flakes were purchased commercially (Goodfellow and Alfa Aesar) and were mixed to achieve a 50:50 $\mathrm{Al}: \mathrm{Ni}$ or Al-Mg:Ni chemistry, and the laminate powders were fabricated in-house through a combination of rolling and grinding to achieve a 52:48 Al:Ni chemistry and an average reactant spacing of $1.5 \mu \mathrm{m}[10]$. The 52:48 and the 50:50 Al:Ni mixtures are expected to form the $\mathrm{B} 2$ $\mathrm{NiAl}$ intermetallic upon reaction, based on the Al:Ni equilibrium phase diagram. An Al-8 at $\% \mathrm{Mg}$ alloy powder was also chosen as a replacement for the $\mathrm{Al}$ powder for two reasons. First, it is a dual phase alloy with a lower melting temperature than pure Al. (The eutectic melting temperature is only $450{ }^{\circ} \mathrm{C}$ on the $\mathrm{Al}$-rich side of the $\mathrm{Al}-\mathrm{Mg}$ phase diagram). The lower melting 
temperature should speed mixing of $\mathrm{Ni}$ into the $\mathrm{Al}-\mathrm{Mg}$ reactant because it will melt earlier in the reaction process as the reaction self-propagates by a given location. Second, the two-phase alloy will be harder than pure $\mathrm{Al}$ due to precipitation hardening and should force more deformation in the Ni phase during the swaging process. [50-51]

An Instron 5582 load frame was used to compact mixed, loose powders into $15 \mathrm{~mm}$ OD stainless steel tubes to $39.3 \mathrm{MPa}$. The process of mixing and packing was completed in five steps using $20 \mathrm{~g}$ quantities in each step so as to minimize segregation of powders. The calculated theoretical density after compacting was approximately $60 \%$. The starting tubes, which were $\sim 40$ $\mathrm{cm}$ in length, were plugged at both ends with $\mathrm{Al}$ rods to keep the powder from spilling out during swaging. The bottom rod was $\sim 20 \mathrm{~cm}$ long while the top plug was only $2.54 \mathrm{~cm}$ long. Each tube had its diameter reduced from $15 \mathrm{~mm}$ to $6.35 \mathrm{~mm}$ as shown in Figure 1(a) through a series of 5 reductions and to $2.54 \mathrm{~mm}$ through a second series of 5 reductions, all with a Fenn $3 \mathrm{~F}$ rotary swager. After reaching a $6.35 \mathrm{~mm} \mathrm{OD}$, approximately $45 \mathrm{~cm}$ were cut from the front end of the $\sim 60 \mathrm{~cm}$ long tube. The remaining sample was swaged to a $2.54 \mathrm{~mm}$ OD. After swaging, the steel jackets around the samples were removed by milling one side of the rod and peeling off the jacket. Once free of the jackets, samples were cut into 3 sections to explore variations in density along the length of the swaged rods. To maintain a uniform test condition, velocity, ignition, and calorimetry test specimens were taken from the front section of each rod.

\subsection{Sample Characterization}

To characterize the microstructure of samples, specimens were cut normal to and along the length of each swaged rod, mounted in epoxy, and then polished using 320 grit sandpaper and 9 $\mu \mathrm{m}, 3 \mu \mathrm{m}$ and $.05 \mu \mathrm{m}$ diamond suspensions. The polished specimens were viewed using scanning electron microscopy (SEM).

After gathering SEM images, the average reactant spacing was assessed by counting the number of times that $\mathrm{Al} / \mathrm{Ni}$ or $\mathrm{Al}-\mathrm{Mg} / \mathrm{Ni}$ interfaces intersect a line of given length. This process was repeated 3 times per image with a total of 5 images being analyzed per sample. Average 
reactant spacing is defined by dividing the total length of line by twice the number of intersections (as average reactant spacing is $1 / 2$ of the average reactant width).

The average density of each sample was determined by placing approximately $1 \mathrm{~g}$ of swaged compact into a Micromeritic Accupyc II gas chamber pycnometer using a load fill of 19.5 PSI He gas. Differential scanning calorimetry was performed on 8 to $10 \mathrm{mg}$ of each sample in a Perkin Elmer Pyris 7 DSC. Test specimens were heated from $50{ }^{\circ} \mathrm{C}$ to $725^{\circ} \mathrm{C}$ at $40{ }^{\circ} \mathrm{C}$ per minute in flowing Ar. Two scans were performed; the first is used to identify exothermic peaks generated by irreversible formation reactions and the second is used as a baseline and is subtracted from the first to determine the net heat flow [40]. This net heat flow is integrated from $50{ }^{\circ} \mathrm{C}$ to $725^{\circ} \mathrm{C}$ to obtain a heat of reaction for each sample.

A home-built hot plate was used to determine the ignition temperature for each sample in air [20]. Starting at $350{ }^{\circ} \mathrm{C}, 10$ specimens were dropped individually onto the heated plate and the onset of ignition was determined visually. The temperature was increased in $5{ }^{\circ} \mathrm{C}$ increments until we observed that when 10 specimens were dropped on the hot plate, all 10 ignited at that temperature. At each test temperature fresh powders were used. Cylindrical samples with a length of 25-30 mm were ignited with a capacitance discharge to measure the velocity of selfpropagating reactions using an optical camera. The velocity experiments were conducted on a fire brick, in air and at room temperature and pressure. After testing for both ignition and velocity, the phases of the reacted samples were characterized using a Phillips X'pert (PANanalytical) X-Ray diffractometer (XRD) and symmetric scans.

\section{Results}

Average densities for each of the 5 mechanically processed samples are displayed in Figure 2 for both $6.35 \mathrm{~mm}$ and $2.54 \mathrm{~mm}$ reductions. We calculate that the average densities range from $\sim 95 \%$ dense to $100 \%$.

Cross-sectional images taken along the length of each swaged sample are displayed in Figure 3, showing the discontinuous layered structure for the $\mathrm{P} / \mathrm{P}$ and $\mathrm{P} / \mathrm{F}$ samples and the more 
uniformly layered microstructures for the laminate powders that were initially refined by rolling. Most samples were almost fully dense, but as Figure 4 identifies, pores do form in the compacts containing Al-Mg powders and Ni flakes. The additional swaging from a $6.35 \mathrm{~mm}$ diameter to a $2.54 \mathrm{~mm}$ diameter consistently reduces the average reactant spacing as shown in Figure 5, particularly for the flake containing samples. Substitution of Al-Mg powders for Al powders does not appear to alter the average reactant spacing, while substitution of $\mathrm{Ni}$ flake for $\mathrm{Ni}$ powders increases the average spacing and its standard deviation significantly. Both increases are attributed to clumping of the Ni flakes during compaction and potentially could be mitigated with more effective mixing prior to compaction.

Figure 6(a) shows typical DSC curves for each of the five different samples, for both radial reductions, $6.35 \mathrm{~mm}$ and $2.54 \mathrm{~mm}$. Each sample has two unique and reproducible exotherms that corresponds to phase transformations at different temperatures. Based on XRD scans of quenched samples, the $\mathrm{Al}_{3} \mathrm{Ni}$ intermetallic forms in the first exotherm and the $\mathrm{Al}_{3} \mathrm{Ni}_{2}$ and AlNi intermetallics form in the second exotherm. The temperatures for the first exothermic peak decrease consistently in Figure 6(b) with the additional swaging from a $6.35 \mathrm{~mm}$ diameter to a $2.54 \mathrm{~mm}$ diameter, similar to the average reactant spacings in Figure 5. Within this consistent drop in peak positions, the powder/powder (P/P) samples exhibited the greatest peak shift compared to the powder/flake (P/F) and laminate powder (LP) samples. The heats of reaction measured using multiple DSC scans are plotted in Figure 7 for each of the samples and their respective reductions. Note that while the measured heats do not vary with additional swaging for the Al:Ni P/P, Al-Mg:Ni P/F, and Al:Ni LP samples, there is a significant decrease for the Al:Ni P/F and the Al-Mg:Ni P/P samples.

The temperatures at which self-sustaining reactions could be ignited on a hot plate in $100 \%$ of the tested specimens are plotted in Figure 8(a). Note that the ignition temperatures decrease with additional swaging, similar to the DSC peak temperatures in Figure 6(b). For comparison, the ignition temperatures are plotted along with the temperatures for the first DSC peaks for the $6.35 \mathrm{~mm}$ and $2.54 \mathrm{~mm}$ diameter samples in Figures 8(b) and (c), respectively. Both sets of temperatures vary in a consistent manner from sample to sample, suggesting a correlation between the solid-state formation of the $\mathrm{Al}_{3} \mathrm{Ni}$ intermetallic in the DSC scans and the ignition of 
the self-sustaining reaction. By comparing Figures 8(b) and (c) one can see that the ignition temperatures drop more than the DSC peak temperatures with additional swaging from a 6.35 $\mathrm{mm}$ diameter to a $2.54 \mathrm{~mm}$ diameter.

Self-propagating reactions could not be ignited in the $6.35 \mathrm{~mm}$ diameter powder/powder and powder/flake samples using an electrical discharge. Reactions quenched in all cases. However, self-propagating reactions could be ignited in most of the $2.35 \mathrm{~mm}$ diameter samples. Reactions propagated in all tests of Al-Mg:Ni P/P and Al:Ni LP specimens and for these samples average velocities are shown. Formation reactions did not self-propagate consistently in the $\mathrm{Al}: \mathrm{Ni} \mathrm{P} / \mathrm{P}$ and the Al-Mg:Ni P/F samples and only one measured velocity is shown in Figure 9 for each. Reactions did not self-propagate at all in the Al:Ni P/F specimens. In all cases of propagation, the reactions could be visually observed to proceed in an unsteady manner, similar to that reported by others $[25,32,38,42]$.

After self-propagation, samples were characterized using symmetric X-ray diffraction (XRD) to identify the final reacted phases. For the Al:Ni samples, we see only peaks for the B2 $\mathrm{NiAl}$ intermetallic except for the Al:Ni LP sample, as shown in Figure 10. This sample has a larger heat of reaction, a faster reaction velocity, and likely reacts more completely, with a higher maximum temperature. The higher reaction temperature may explain the onset of noticeable oxidation and the appearance of the large $\mathrm{Al}_{2} \mathrm{O}_{3}$ peak in the XRD scan of the $\mathrm{Al}$ :Ni LP sample. The B2 NiAl intermetallic is the dominating final phase for $\mathrm{Mg}$ containing samples as well. However, a small peak appears for these two samples that can be indexed with $\mathrm{MgO}$. We attribute its appearance to the evaporation of $\mathrm{Mg}$ from the samples during reaction propagation, and its deposition on the sample surface. This has been observed in other materials this group has studied on [52]. There is no difference in the final phases for the $2.54 \mathrm{~mm}$ and $6.35 \mathrm{~mm}$ samples, suggesting that the swaging process maintains a chemistry that is uniform enough to fully react and form the same final phases on the time scale of the self-propagating reaction fronts. 


\section{Discussion}

\subsection{Powder Densification}

With each swaging pass of the powder-filled steel tubes their diameters are reduced by $\sim 15 \%$ and powders within the tube are deformed. After the $4^{\text {th }}$ swaging pass this deformation is thought to have densified the powder compacts almost completely due to the change in volume.

To assess the densification of the compacts as a function of powder chemistry and geometry, we measured density along the length of the $6.35 \mathrm{~mm}$ and $2.54 \mathrm{~mm}$ diameter swaged rods. The values measured for the front, middle and rear sections of the $6.35 \mathrm{~mm}$ and the 2.54 mm diameter rods show minimal scatter and no clear variation along their $45 \mathrm{~cm}$ lengths. This indicates a relatively uniform densification and chemistry. The Al:Ni P/P and the Al-Mg:Ni P/P samples appear to densify further with additional swaging. Note that the $2.54 \mathrm{~mm}$ diameter samples have a higher density, $99.3 \%$ and $100 \%$ respectively, compared to the $6.35 \mathrm{~mm}$ diameter samples. This can be attributed, in part, to the relatively soft nature of the $\mathrm{Al}, \mathrm{Al}-\mathrm{Mg}$ and $\mathrm{Ni}$ powders, compared to that of the Ni flakes, and $\mathrm{Al} / \mathrm{Ni}$ laminate powders.

In contrast to the powder-only samples, the density appears to decrease when swaging from a $6.35 \mathrm{~mm}$ diameter to a $2.54 \mathrm{~mm}$ diameter for P/F and LP samples. As tube diameters shrink during each swaging pass, the powders must deform and thereby elongate or they must slide past each other to accommodate this reduction. The harder Ni flakes and laminate Ni:Al particles are less likely to deform and therefore more likely to slide and rotate past each other to accommodate tube reductions. This sliding and rotation could create small voids during swaging. Examples of such pores are shown in Figure 4 for the Al-Mg:Ni P/F samples swaged to diameters of $6.35 \mathrm{~mm}$ and $2.54 \mathrm{~mm}$.

\subsection{Microstructure}

Microstructural analysis shows a consistent decrease in the average reactant spacing on going from the $6.35 \mathrm{~mm}$ to the $2.54 \mathrm{~mm}$ samples (Figure 5). Regardless of the starting powder 
geometry or chemistry there is a noticeable refinement in the final microstructure with additional swaging reductions. This trend is even seen for the heavily cold-worked laminate powders, as a significant decrease can be found in the average reactant spacing. Figure 5 also shows that the standard deviation in the average reactant spacing generally decreases with additional refinement, particularly in the $\mathrm{P} / \mathrm{P}$ samples, signifying a more uniform microstructure within the samples.

The goal for substituting Ni flake for the Ni powder was to produce a finer microstructure or average reactant spacing and hence more reactive samples. Unfortunately, the opposite impact was observed (Figure 5). The addition of Ni flake resulted in a coarser microstructure, which in turn produced less reactive samples. When comparing DSC and ignition data in Figures 6(b), 8(b), and 8(c) for powder and flake samples with similar chemistries, we see that the substitution of Ni flake leads to higher DSC peak temperatures and higher ignition temperatures and hence less reactive material. The same is true for the reaction velocities in Figure 9. Samples that contain Ni powder propagate more rapidly than those containing Ni flake, for both the $\mathrm{Al}$ and $\mathrm{Al}-\mathrm{Mg}$ chemistries. (Note: reactions within the $\mathrm{Al}: \mathrm{Ni} \mathrm{P} / \mathrm{F}$ samples could not self-propagate at all.) We attribute the degradation of reaction properties with the substitution of Ni flake primarily to the agglomeration of the flakes during mixing with the $\mathrm{Al}$ or Al-Mg powders. A better distribution of the flakes could still lead to improved properties and will be attempted in future work.

When Al-Mg powders replaced $\mathrm{Al}$ powders in the compacts, the average reactant spacing increased for the $6.35 \mathrm{~mm}$ compacts but was similar for the $2.54 \mathrm{~mm}$ compacts as shown in Figure 5. The softer pure Al powders likely deform more easily than the Al-Mg powders in the first series of swaging steps to a $6.35 \mathrm{~mm}$ diameter but then strain harden and compact in a similar manner in the latter steps of swaging to the $2.54 \mathrm{~mm}$ diameter.

\subsection{Calorimetry and Ignition Data}

As Figures 6(b) and 8(a) illustrate, additional swaging lowers onset temperatures for the formation reactions. The DSC and ignition data show consistent and repeatable trends supporting this claim. With the additional swaging from $6.35 \mathrm{~mm}$ to $2.54 \mathrm{~mm}$ diameters the 
temperatures for the first DSC peaks shift approximately $42{ }^{\circ} \mathrm{C}$ lower for the $\mathrm{P} / \mathrm{P}$ samples, approximately $35^{\circ} \mathrm{C}$ lower for the P/F samples, and only $12{ }^{\circ} \mathrm{C}$ lower for the LP samples. The shift in peak positions strongly supports a refinement of the microstructure and a reduction in the average reactant spacing. It also suggests refinement is largest for the soft, single-phase powder samples and smallest for the laminate powder samples (LP) that were heavily worked prior to compaction. Similar to DSC peak temperatures, we see in Figure 8(a) that the ignition thresholds for all five samples decrease significantly after the samples are swaged from $6.35 \mathrm{~mm}$ to 2.54 $\mathrm{mm}$ diameters. The decrease is approximately $100{ }^{\circ} \mathrm{C}$ for the $\mathrm{P} / \mathrm{P}$ samples, approximately $75^{\circ} \mathrm{C}$ for the P/F samples, and approximately $50{ }^{\circ} \mathrm{C}$ for the LP samples. These differences in ignition temperature correlate very well with the changes in DSC peak temperatures as shown in Figures 8(b) and (c).

As reported in earlier publications [10, 35-36, 39-40, 42], reductions in average reactant spacing allow atomic mixing and phase formation to occur at lower temperatures in DSC scans, simply due to smaller average diffusion distances. The smaller diffusion distances also lead to lower ignition temperatures, even ones well below the melting point of Al. These dependences and low values have been reported earlier in vapor deposited $[32,34]$ and in mechanically fabricated materials [10, 42, 45]. More importantly, for non-uniform microstructures, shifts in DSC peaks and ignition temperatures are thought to be better indicators of changes in average microstructure than the analysis of multiple micrographs [10, 42]. The DSC and ignition test specimens average over much larger volumes than do the micrographs that are used to quantify reactant spacing. The test specimens capture a broader fraction of the reactant spacing distribution. Thus, the shifts of the first exothermic peaks in Figure 6(a) and the drops in the ignition temperatures in Figure 8(a) are clear indicators of microstructural refinement within the compacts on going from a $6.35 \mathrm{~mm}$ diameter to a $2.54 \mathrm{~mm}$ diameter. We also suggest that more refinement and further reductions in DSC peak temperatures and ignition temperatures are possible with additional swaging.

As noted above, when Ni flake is substituted for Ni powder the flakes tend to clump and the average reactant spacing increases for the $6.35 \mathrm{~mm} \mathrm{Al}$ and $\mathrm{Al}-\mathrm{Mg}$ samples, as shown in Figure 5. This change explains the rise in DSC peak temperatures (Figure 6 (b)) and the ignition temperatures (Figure 8(a)) for the $6.35 \mathrm{~mm}$ samples when comparing $\mathrm{Al}: \mathrm{Ni} \mathrm{P} / \mathrm{P}$ to $\mathrm{Al}: \mathrm{Ni} \mathrm{P} / \mathrm{F}$ 
samples and when comparing Al-Mg:Ni P/P samples to Al-Mg:Ni P/F samples. Larger reactant spacings lead to slower reactions in both cases. Similar changes cannot be identified for the 2.54 mm samples, mainly because too much scatter exists in the reactant spacing data shown in Figure 5.

The laminate Al:Ni powders utilized in this study had an initial average reactant spacing of $1.5 \mu \mathrm{m}[10]$ and through the rotary swaging process this average reactant spacing was decreased significantly. After swaging to an OD of $6.35 \mathrm{~mm}$ the average spacing dropped to 0.35 $\pm 0.08 \mu \mathrm{m}$ and after swaging to a $2.54 \mathrm{~mm}$ OD it dropped to $0.15 \pm 0.02 \mu \mathrm{m}$. These reactant spacings are approximately ten times smaller than those measured for the other samples, as shown in Table 1, and explain why the composite powder compacts have the lowest DSC peak temperatures (Figure 6 (b)), the largest DSC heats of reaction (Figure 7), the lowest ignition temperatures (Figure 8(a)) and the highest reaction velocities (Figure 9). Most importantly, the results demonstrate that composite powders can be swaged into dense solids and the associated plastic deformation can refine their microstructures and enhance their reactivity. Extension to ball-milled composite powders is underway.

The substitution of Al-Mg powders for Al powders also offers a consistent impact on reaction properties. While reactant spacing is not altered significantly by the substitution of Al$\mathrm{Mg}$ powders for $\mathrm{Al}$ powders (Figure 5), the lower melting point of the Al-Mg alloy, compared to the pure Al powders, appears to lower peak temperatures in the DSC scans (Figure 6(b)) as well as ignition temperatures (Figure 8(a)). The substitution also leads to higher reaction velocities for the $\mathrm{Al}-\mathrm{Mg}$ containing $\mathrm{P} / \mathrm{P}$ samples and enables propagation to begin in the case of the $\mathrm{P} / \mathrm{F}$ samples. Thus, substitution of Al-Mg powders for Al powders leads to a clear enhancement of reactivity, even though the scale of the microstructure remains relatively constant.

Turning to the heats of reaction, Figure 7 shows that the DSC measured heats remain statistically constant for the Al:Ni P/P, Al-Mg:Ni P/F, and Al:Ni LP systems following additional swaging, but decrease unexpectedly for the $2.35 \mathrm{~mm} \mathrm{Al:Ni} \mathrm{P/F} \mathrm{and} \mathrm{Al-Mg:Ni} \mathrm{P/P}$ samples compared to the corresponding $6.35 \mathrm{~mm}$ samples. While the reasons for this decrease are not yet obvious, we suggest that one possible explanation is a reduced degree or volume of melting in the $2.35 \mathrm{~mm}$ samples. For the $\mathrm{Al}: \mathrm{Ni} \mathrm{P} / \mathrm{F}$ samples there is a major DSC peak at $660^{\circ} \mathrm{C}$ that indicates melting of $\mathrm{Al}$, leading to rapid exothermic mixing of $\mathrm{Al}$ and $\mathrm{Ni}[10]$. This peak is 
substantial in size for the $6.35 \mathrm{~mm} \mathrm{Al:Ni} \mathrm{P/F} \mathrm{specimens} \mathrm{but} \mathrm{decreases} \mathrm{significantly} \mathrm{in} \mathrm{the} 2.35$ mm specimens. The additional refinement imparted to the $2.35 \mathrm{~mm}$ specimens can lead to more solid-state mixing and intermetallic formation prior to $660^{\circ} \mathrm{C}$ in the $\mathrm{DSC}$ scans. Thus, less $\mathrm{Al}$ is available to melt and hence less rapid mixing occurs when the remaining Al does melt. A similar reduction in melting and mixing could also be occurring in the Al-Mg:Ni P/P $2.35 \mathrm{~mm}$ samples, but the reduction is less clear at the lower melting temperature for the $\mathrm{Al}-\mathrm{Mg}$ alloy.

\subsection{Reaction Velocity}

The rate at which exothermic formation reactions can self-propagate is the most common means for assessing changes in reactivity. However, we could not ignite self-propagating reactions in any of the $6.35 \mathrm{~mm}$ samples. Thus, a quantitative assessment of how reaction velocities vary with the degree of swaging is not possible for a given chemistry. However, the fact that propagation is enabled for four of the samples by swaging to the smaller $2.54 \mathrm{~mm}$ diameter does indicate that reactivity and velocity increase with swaging. Furthermore, Figure 9 shows that for the Al:Ni chemistry, the finer microstructure in the Al:Ni LP sample yields the highest velocity. The data in Figure 9 also establish that the substitution of Al-Mg powders for Al powders produces higher reaction velocities for both the $\mathrm{P} / \mathrm{P}$ and the $\mathrm{P} / \mathrm{F}$ samples. These increases are likely due to faster reaction kinetics alone, as the theoretical heats of reaction go down slightly and the average reactant spacing does not change significantly (Figure 5) with the addition of $\mathrm{Mg}$ in the $2.35 \mathrm{~mm}$ samples.

Taken together, the microstructure, DSC, ignition, and velocity data all establish that reactive materials can be successfully fabricated by rotary swaging of $\mathrm{Al}: \mathrm{Ni}$ and $\mathrm{Al}-\mathrm{Mg}: \mathrm{Ni}$ powder compacts. Other reaction chemistries can be fabricated, and while not successful here, other particle geometries can be utilized as well. The ability to combine a variety of low cost powders into refined reactive composites with varying degrees of reactivity suggests this fabrication technique holds promise for the future. In addition, the ability to include laminate or composite particles will expand its potential application as a low cost fabrication method. 


\section{Conclusion}

Using rotary swaging of steel tubes packed with powders we fabricated Al:Ni and Al$\mathrm{Mg}: \mathrm{Ni}$ composites that are $\sim 95 \%$ to $100 \%$ dense. The spacing of reactants in the swaged composites decreases with additional swaging and leads to enhanced reactivity as shown by lower DSC peak temperatures, lower ignition temperatures, and the enabling of reaction selfpropagation within the composites. Substituting Al-Mg alloy powders for $\mathrm{Al}$ powders also enhances reactivity leading to lower DSC peak temperatures, lower ignition temperatures and faster reaction velocities compared to compacts with Al powders. Substituting Ni flake for the Ni powder, though, showed no improvement in reaction properties, primarily due to clumping of the Ni flakes during initial mixing and compaction. The higher reactivity of the Al:Ni laminate powder samples establishes the ability to swage composite powders into attractive reactive materials and expands the potential application of rotary swaging.

\section{Acknowledgements}

The authors would like to thank Mark Koontz for his assistance in taking SEM images. The authors would also like to thank Frank Cook and Mike Franckowiak for their assistance in machining samples for analysis. This work was funded by the Office of Naval Research under the Multiple University Research Initiative grant award N00014-07-1-0740.

\section{References}

[1] A. S. Mukasyan, A. S. Rogachev, and S. Aruna, Combustion synthesis in nanostructured reactive systems, Adv. Powder Technol. (2015) doi: 10/ 1016/j.apt.2015.03.013.

[2] G. Liu, J. Li, and K. Chen, Combustion synthesis of refractory and hard materials: A review, Int. J. Refractory Met. Hard Mater. 39 (2013) 90-102.

[3] K. Morsi, The diversity of combustion synthesis processing: a review, J. Mater. Sci. 47 (2012) 68-92. 
[4] A. S. Rogachev, A. S. Mukasyan, Combustion of heterogeneous nanostructural systems (Review), Combust. Expl. Shock Waves 46 (2010) 243-266.

[5] A. G. Merzhanov, and P. Borovinskaya, Historical retrospective of SHS: An autoreview, Int. J. SHS. 17 (2008) 242-265.

[6] A. Makino, Fundamental aspects of the heterogeneous flame in the self-propagating hightemperature synthesis (SHS) process, Prog. Energy Combust. Sci. 27 (2001) 1-74.

[7] J. J. Moore, and H. J. Feng, Combustion synthesis of advanced materials: Part I. Reaction parameters, Prog. Mater. Sci. 39 (1995) 243-273.

[8] Z.A. Munir, J.B. Holt, Combustion and Plasma Synthesis of High-Temperature Materials, California University Davis, U.S., 1990.

[9] A. Hadjiafxenti, I. E. Genduz, C. C. Doumanidis, and C. Rebholz, Spark ignitable ball milled powders of $\mathrm{Al}$ and $\mathrm{Ni}$ at NiAl composition, Vac. 101 (2014) 275-278.

[10] A. K. Stover, N. M. Krywopusk, J. D. Gibbins, and T. P. Weihs, Mechanical fabrication of reactive metal laminate powders. J. Mater. Sci. 49 (2014) 5821-5830.

[11] D. Erdeniz, T. Ando, Fabrication of micro / nano structured aluminum - nickel energetic composites by means of ultrasonic powder consolidation, Inter. J. Mater. Res. 104 (2013) $5-10$.

[12] B. A. Mason, L. J. Groven, and S. F. Son, The role of microstructure refinement on the impact ignition and combustion behavior of mechanically activated $\mathrm{Ni} / \mathrm{Al}$ reactive composites, J. Appl. Phys. 114 (2013) 113501-7.

[13] A. S. Rogachev, N. F. Shkodich, S. G. Vadchenko, F. Baras, D. Y. Kovalev, S. Rouvimov, A. A. Nepapushev, and A. S. Mukasyan, Influence of the high energy ball milling on structure and reactivity of the $\mathrm{Ni}+\mathrm{Al}$ powder mixture, J. Alloys Compd. 577 (2013) 600-605.

[14] Priya R. Santhanam, Edward L. Dreizin, Predicting conditions for scaled-up manufacturing of materials prepared by ball milling, Powder Technol. 221 (2012) 403411.

[15] K. V. Manukyan, B. A. Mason, L. J. Groven, Y. Lin, M. Cherukara, S. F. Son, A. Strachan, and A. S. Mukasyan, Tailored reactivity of $\mathrm{Ni}+\mathrm{Al}$ nanocomposites: microstructural correlations, J. Phys. Chem. C 116 (2012) 21027-21038. 
[16] R.V. Reeves, A. S. Mukasyan, and S. F. Son, M. L. Elert, W. T. Butler, J. P. Borg, J. L. Jordan, and T. J. Vogler, Microstructural effects on ignition sensitivity in Ni/Al systems subjected to high strain rate impacts, AIP Conference Proceedings-American Inst. Phys. 1426 (2012) 539-542.

[17] A. Bacciochini, M. I. Radulescu, Y. Charron-Tousignant, J. V. Dyke, M. Nganbe, M. Yandouzi, J. J. Lee, and B. Jodoin, Enhanced reactivity of mechanically-activated nanoscale gasless reactive materials consolidated by coldspray, Surface \& Coatings Technol. 206 (2012) 4343-4348.

[18] E. B. Herbold, N. N. Thadani, and J. L. Jordan, Observation of a minimum reaction initiation threshold in ball-milled $\mathrm{Ni}+\mathrm{Al}$ under high-rate mechanical loading, J. Appl. Phys. 109 (2011) 066108-3.

[19] E. B. Herbold, J. L. Jordan, and N. N. Thadani, Effects of processing and powder size on microstructure and reactivity in arrested reactive milled Al+ Ni, Acta Mater. 59 (2011) 6717-6728.

[20] G. M. Fritz, H. Joress, and T. P. Weihs, Enabling and controlling slow reaction velocities in low-density compacts of multilayer reactive particles, Combust. Flame 158 (2011) 1084-1088.

[21] A. Hadjiafxenti, I.E. Gunduz, C. Tsotsos, T. Kyratsi, S. M. Aouadi, C. C. Doumanidis, and C. Rebholz, The influence of structure on thermal behavior of reactive Al-Ni powder mixtures formed by ball milling, J. Alloys Compd. 505 (2010) 467-471.

[22] A. Hadjiafxenti, I. E. Gunduz, C. Tsotsos, T. Kyratsi, C. C. Doumanidis, and C. Rebholz, Synthesis of reactive Al/Ni structures by ball milling, Intermetallics 18 (2010) 22192223.

[23] E. M. Hunt and M. L. Pantoya, Impact sensitivity of intermetallic nanocomposites: A study on compositional and bulk density, Intermetallics 18 (2010) 1612-1616.

[24] E. L. Dreizin, Metal-based reactive nanomaterials, Prog. Energy Combust. Sci. 35 (2009) $141-167$.

[25] A. S. Mukasyan, A. S. Rogachev, Discrete reaction waves: gasless combustion of solid powder mixtures, Prog. Energy Combust. Sci. 34 (2008) 377-416. 
[26] B. S. Bockmon, M. L. Pantoya, S. F. Son, B. W. Asay, and J. T. Mang, Combustion velocities and propagation mechanisms of metastable interstitial composites, J. Appl. Phys. 98 (2005) 064903.

[27] E. M. Hunt, K. B. Plantier, and M. L. Pantoya, Nano-scale reactants in the selfpropagating high-temperature synthesis of nickel aluminide, Acta Mater. 52 (2004) 3183319.

[28] V. V. Barzykin, A. G. Merzhanov, and A. G. Strunina, Ignition of heterogeneous systems containing condensed reaction products, Symp. (Int.) Combust. 23 (1991) 1725-1731.

[29] S.W. Dean, J.K. Potter, R.A. Yetter, T.J. Eden, V. Champagne, and M. Trexler, "Energetic intermetallic materials formed by cold spray," Intermetallics 43 (2013) 121130.

[30] V. Champagne, The Cold Spray Materials Deposition Process: Fundamentals and Applications, Woodhead Publishing Limited, Abington Hall, Abington Cambridge, England, 2003.

[31] D.S. Sundaram and V. Yang, Effect of packing density on flame propagation of nickelcoated aluminum particles, Combust. Flame 161 (2014) 2916-2923.

[32] D.P. Adams, Reactive multilayers fabricated by vapor deposition: A critical review, Thin Solid Films, 576 (2015) 98-128

[33] R. Reeves and D. Adams, Reaction instabilities in Co/Al nanolaminates due to chemical kinetics variation over micron-scales, J. Appl. Phys. 115 (2014) 044911.

[34] G. M. Fritz, S. J. Spey, M. D. Grapes, and T. P. Weihs, Thresholds for igniting exothermic reactions in $\mathrm{Al} / \mathrm{Ni}$ multilayers using pulses of electrical, mechanical, and thermal energy, J. Appl. Phys. 113 (2013) 014901.

[35] R. Knepper, M. R. Snyder, G. M. Fritz, K. Fisher, O. M. Knio, and T. P. Weihs, Effect of varying bilayer spacing distribution on reaction heat and velocity in reactive $\mathrm{Al} / \mathrm{Ni}$ multilayers, J. Appl. Phys. 105 (2009) 083504.

[36] A. S. Rogachev, Exothermic reaction waves in multilayer nanofilms, Russ. Chem. Rev. 77 (2008) 21-37.

[37] J. C. Gachon, A. S. Rogachev, H. E. Grigoryan, E. V. Illarionova, J. J. Kuntz, D. Y. Kovalev, and P. A. Tsygankov, On the mechanism of heterogeneous reaction and phase formation in Ti/Al multilayer nanofilms, Acta Mater. 53 (2005) 1225-1231. 
[38] J. P. McDonald, V. C. Hodges, E. D. Jones, and D. P. Adams, Direct observation of spinlike reaction fronts in planar energetic multilayer foils, Appl. Phys. Lett. 94 (2003) 034102.

[39] A. J. Gavens, D. V. Heerden, A. B. Mann, M. E. Reiss, and T. P. Weihs, Effect of intermixing on self-propagating exothermic reactions in $\mathrm{Al} / \mathrm{Ni}$ nanolaminate foils, $\mathrm{J}$. Appl. Phys. 87 (2000) 1255-1263.

[40] C. Michaelsen, K. Barmak, and T. P. Weihs, Investigating the thermodynamics and kinetics of thin film reactions by differential scanning calorimetry, J. Phys. D; Appl. Phys. 30 (1997) 3167-3186.

[41] Ihab Sraj, Paul E. Specht, Naresh N. Thadani, T. P. Weihs, O. M. Knio, Numerical simulation of shock initiation of Ni/Al multilayered composites, J. Appl. Phys. 115 (2014) 023515.

[42] A. K. Stover, N. M. Krywopusk, G. M. Fritz, S. C. Barron, J. D. Gibbins, and T. P. Weihs, An analysis of the microstructure and properties of cold-rolled Ni:Al laminate foils, J. Mater. Sci. 48 (2013) 5917-5929.

[43] Kecskes, Lazlo J; Qiu, Xiaotun; Lin, Ranran; et al., Combustion Synthesis Reaction Behavior of Cold-Rolled Ni/Al and Ti/Al Multilayers, Report No. ADA548641, Army Research Laboratory, 2011.

[44] X. Qiu, J. Graeter, L. Kecskes, and J. Wang, Exothermic reactions in cold-rolled Ni/Al reactive multilayer foils, J. Mater. Res. 23 (2008) 367-375.

[45] H. Sieber, J. S. Park, J. Weissmüller, and J. H. Perepezko, Structural evolution and phase formation in cold-rolled aluminum-nickel multilayers. Acta Mater. 49 (2001) 11391151.

[46] M. Abdulstaar, Ehab A. El-Danaf, Nurhadi S. Waluyo, and Lothar Wagner, "Severe plastic deformation of commercial purity aluminum by rotary swaging: Microstructure evolution and mechanical properties," Mater. Sci. Eng.: A, 565 (2013) 351-358.

[47] A. Ghaei, M. R. Movahhedy, and A. Karimi Taheri, Finite element modelling simulation of radial forging of tubes without mandrel. Mater. Des. 29 (2008) 867-872.

[48] A. Ghaei, A. Karimi Taheri, and M. R. Movahhedy, A new upper bound solution for analysis of the radial forging process. Int. J. Mech. Sci. 48 (2006) 1264-1272. 
[49] E. Rauschnabel, and V. Schmidt, "Modern applications of radial forging and swaging in the automotive industry,” J. Mater. Process. Technol. 35 (1992) 371-383.

[50] D. Witkin, Z. Lee, R. Rodriguez, S. Nutt, E. Lavernia, Al-Mg alloy engineered with bimodal grain size for high strength and increased ductility, Scripta Mater. 49 (2003) 297-302.

[51] Y. Aly, E. L. Dreizin, Ignition and combustion of Al Mg alloy powders prepared by different techniques, Combust. Flame 162 (2015) 1440-1447.

[52] K. R. Overdeep, K. J.T. Livi, D. J. Allen, N. G. Glumac, T. P. Weihs, Using magnesium to maximize heat generated by reactive $\mathrm{Al} / \mathrm{Zr}$ nanolaminates, Combust. Flame 162 (2015) 2855-2864.

[53] F. R. de Boer, R. Boom, W. C. M. Mattens, A. R. Miedma, and A. K. Niessen Cohesion in Metals: Transition Metal Alloys, Elsevier Science Publishers B.V., Amsterdam, NL, 1989. 


\begin{tabular}{|c|c|c|c|c|}
\hline & $\begin{array}{c}\text { Compact } \\
\text { Chemistry } \\
\text { (at\%) }\end{array}$ & $\begin{array}{l}\text { Initial Powder Shape } \\
\text { and Size (mesh) }\end{array}$ & $\begin{array}{l}\text { Average Reactant } \\
\text { Spacing }(\mu \mathrm{m}) \text { for } \\
6.35 \mathrm{~mm} \text { Samples }\end{array}$ & $\begin{array}{c}\text { Average Reactant } \\
\text { Spacing }(\mu \mathrm{m}) \text { for } 2.54 \\
\text { mm Samples }\end{array}$ \\
\hline Al:Ni P/P & $\begin{array}{l}50 \mathrm{Al} \\
50 \mathrm{Ni}\end{array}$ & $\begin{array}{l}\text { Al: sphere: }-325 \\
\text { Ni: sphere: }-325\end{array}$ & $3.16 \pm .42$ & $2.01 \pm 0.31$ \\
\hline Al:Ni P/F & $\begin{array}{l}50 \mathrm{Al} \\
50 \mathrm{Ni} \\
\end{array}$ & $\begin{array}{l}\text { Al: sphere: }-325 \\
\text { Ni: flake: }-325 \\
\end{array}$ & $6.17 \pm 2.06$ & $1.82 \pm 0.20$ \\
\hline Al-Mg:Ni P/P & $\begin{array}{r}46 \mathrm{Al} \\
4 \mathrm{Mg} \\
50 \mathrm{Ni} \\
\end{array}$ & $\begin{array}{l}\text { Al-Mg: sphere: }-325 \\
\text { Ni: sphere: }-325\end{array}$ & $4.11 \pm 1.06$ & $1.57 \pm 0.31$ \\
\hline Al-Mg:Ni P/F & $\begin{array}{c}46 \mathrm{Al} \\
4 \mathrm{Mg} \\
50 \mathrm{Ni}\end{array}$ & $\begin{array}{l}\text { Al-Mg: sphere: }-325 \\
\text { Ni: flake: }-325\end{array}$ & $8.38 \pm 2.71$ & $1.99 \pm 0.28$ \\
\hline Al:Ni LP & $\begin{array}{l}48 \mathrm{Al} \\
52 \mathrm{Ni}\end{array}$ & $\begin{array}{l}\text { Al:Ni: sphere: } 212- \\
355 \mu \text { m laminate } \\
\text { structure }\end{array}$ & $0.35 \pm 0.08$ & $0.15 \pm 0.02$ \\
\hline
\end{tabular}

Table 1: Chemistries, particle geometries and average reactant spacings for the five compacted samples. $(\mathrm{P}=$ particle, $\mathrm{F}=$ flake, and $\mathrm{LP}=$ laminate particle.) The average reactant spacing is determined using the lineal intercept method where the $\mathrm{Al} / \mathrm{Ni}$ or $\mathrm{Al}-\mathrm{Mg} / \mathrm{Ni}$ boundaries determine intersections, and the average spacing is equivalent to $1 / 2$ of the average reactant width. 
Figure 1: Schematic diagrams of a 3Fenn Rotary Swager. (a) A front view of the swager showing two dies coming together to deform a metal tube loaded with powder. During operation the swager spins a roll cage lined with rollers that pass over a set of hammers that compression the dies together. (b) A cross-sectional view of a tube being deformed to a smaller diameter by two dies as it is pushed into the swager.

Figure 2: Density measured for specimens taken along the $45 \mathrm{~cm}$ length of the $6.35 \mathrm{~mm}$ diameter and $2.54 \mathrm{~mm}$ diameter swaged rods. The $45 \mathrm{~cm}$ lengths of both the $6.35 \mathrm{~mm}$ and $2.54 \mathrm{~mm}$ samples are cut into three sections (Front, Middle, and Rear). $2.54 \mathrm{~mm}$ samples are averaged and compared to the $6.35 \mathrm{~mm}$ front, middle, and rear samples. Lines located above the samples represent the literature/calculated values for the respective systems. The percentages located on the bottom of each plot are the $\%$ total density for each reduction as derived from the literature/calculated density values. The average value for the rear section of the Al:Ni P/F sample is missing due to a lack of sufficient material following other characterizations.

Figure 3: Cross-sections of each sample taken along their lengths for both reduction diameters: Al:Ni P/P compacts (a) $6.35 \mathrm{~mm}$ and (b) $2.54 \mathrm{~mm}$; Al:Ni P/F compacts (c) $6.35 \mathrm{~mm}$ and (d) $2.54 \mathrm{~mm} ; \mathrm{Al}-\mathrm{Mg}: \mathrm{Ni} \mathrm{P} / \mathrm{P}$ compacts (e) $6.35 \mathrm{~mm}$ and (f) $2.54 \mathrm{~mm}$; Al-Mg:Ni P/F compacts (g) $6.35 \mathrm{~mm}$ and (h) $2.54 \mathrm{~mm}$; and Al:Ni LP compacts (i) $6.35 \mathrm{~mm}$ and (h) $2.54 \mathrm{~mm}$.

Figure 4: Pores seen within longitudinal images of Al-Mg:Ni P/F at $6.35 \mathrm{~mm}$ (a) and $2.54 \mathrm{~mm}$ (b) samples from Figure 2 ( $g$ and $h$ ). The majority of pores appear within agglomerations of Ni flakes and at $\mathrm{Ni} / \mathrm{Al}$ boundaries. Based on density measurements a minimum of 0 vol\% and a maximum of 5 vol\% of voids exist within all of our samples.

Figure 5: Average reactant spacing as determined using the lineal intercept methods and 5 SEM images per sample. The highest standard deviations are seen for the $6.35 \mathrm{~mm}$ samples; the numerical values can be found in Table 1.

Figure 6: (a) Typical DSC curves for each of the 5 samples showing two distinct exotherms, the recorded data is representative of the tirst exotnermic peai. Tine sharp exotherms at $640{ }^{\circ} \mathrm{C}$ for the $\mathrm{Al}: \mathrm{Ni} \mathrm{P} / \mathrm{P}$ and $\mathrm{Al}: \mathrm{Ni} \mathrm{P} / \mathrm{F}$ samples do not vary in temperature and are attributed to the melting of Al. The temperatures for the onsets and peaks of the first exotherms decrease with the additional swaging passes, suggesting that the plastic strain imparted by swaging to a $2.54 \mathrm{~mm}$ diameter reduces the average reactant spacing. (b) Temperatures for the first exothermic peak are plotted and show consistent drops with additional swaging for each sample, with the largest drops seen for the powder/powder samples. 
Figure 7: Heats of reaction for the 5 samples and the two different swaging reductions. Averages were calculated by integrating at least 3 DSC scans, similar to those shown in Figure 5(a). Samples show a similar heat of reaction for both swaging conditions for the Al:Ni P/P, the Al-Mg:Ni P/F, and the Al:Ni LP samples, but there is a drop-off in energy release with greater diameter reductions for the Al:Ni P/F and the Al-Mg:Ni P/P specimens. The heat of reaction for the initial, pre-swaged $\mathrm{Al}$ :Ni laminate powders are shown for comparison. The dashed line represents the literature value for the theoretical heat of mixing for $\mathrm{NiAl}$ [53].

Figure 8: (a) Ignition results for the $2.54 \mathrm{~mm}$ and $6.35 \mathrm{~mm}$ diameter samples. Ignition temperatures decrease for all samples as the degree of swaging increases. The greatest change in temperature appears in the powder/powder systems. (b) Ignition temperatures for $6.35 \mathrm{~mm}$ diameter samples are compared to temperatures for the first exothermic peak in their respective DSC scans. (c) Ignition temperatures for $2.54 \mathrm{~mm}$ diameter samples are compared to temperatures for the first exothermic peak in their respective DSC scans.

Figure 9: Self-propagating reaction velocities for the 5 samples after swaging to a $2.54 \mathrm{~mm}$ diameter. Samples with a lower ignition threshold show faster velocities, however we were unable to achieve propagation in $\mathrm{Al}: \mathrm{Ni} \mathrm{P} / \mathrm{F}$ samples without quenching. Reactions in Al:Ni P/P and Al-Mg:Ni P/F samples did not propagate consistently and only single velocities measurements were obtained for each.

Figure 10: X-ray diffraction patterns of $2.54 \mathrm{~mm}$ samples after self-propagating reactions. Plus signs, circles with vertical lines, and squares represent $\mathrm{NiAl}, \mathrm{Al}_{2} \mathrm{O}_{3}$, and $\mathrm{MgO}$ peaks, respectively. For samples with $\mathrm{Mg}$, we see the NiAl intermetallic, $\mathrm{MgO}$ and possibly some $\mathrm{Al}_{2} \mathrm{O}_{3}$. A strong $\mathrm{Al}_{2} \mathrm{O}_{3}$ peak is seen in the $\mathrm{Al}$ :Ni LP sample. Curves have been shifted vertically for comparison. 

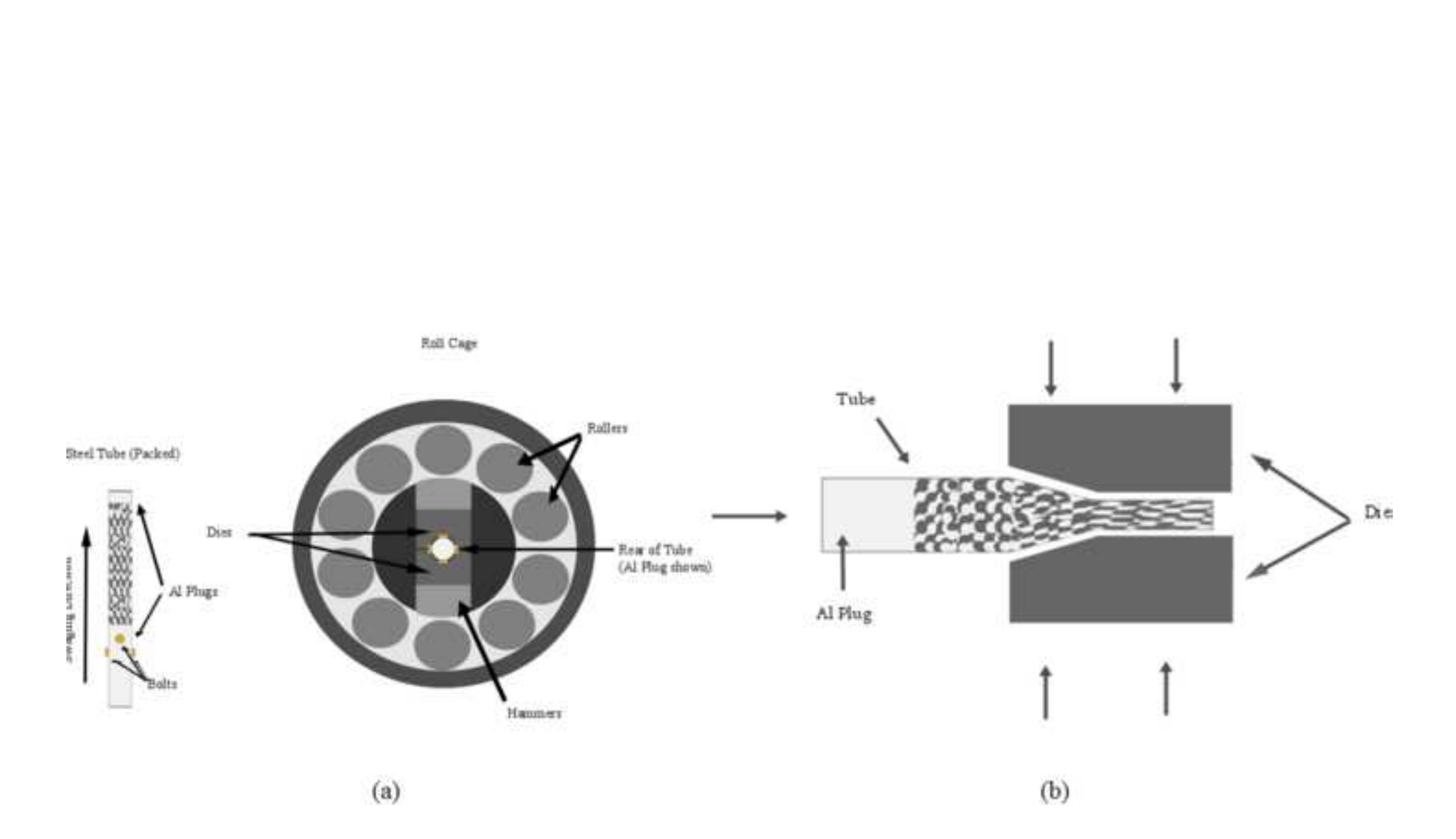

$12+\frac{1}{1}+\frac{1}{1}$

$12+\frac{1}{1}+\frac{1}{1}$

(b)

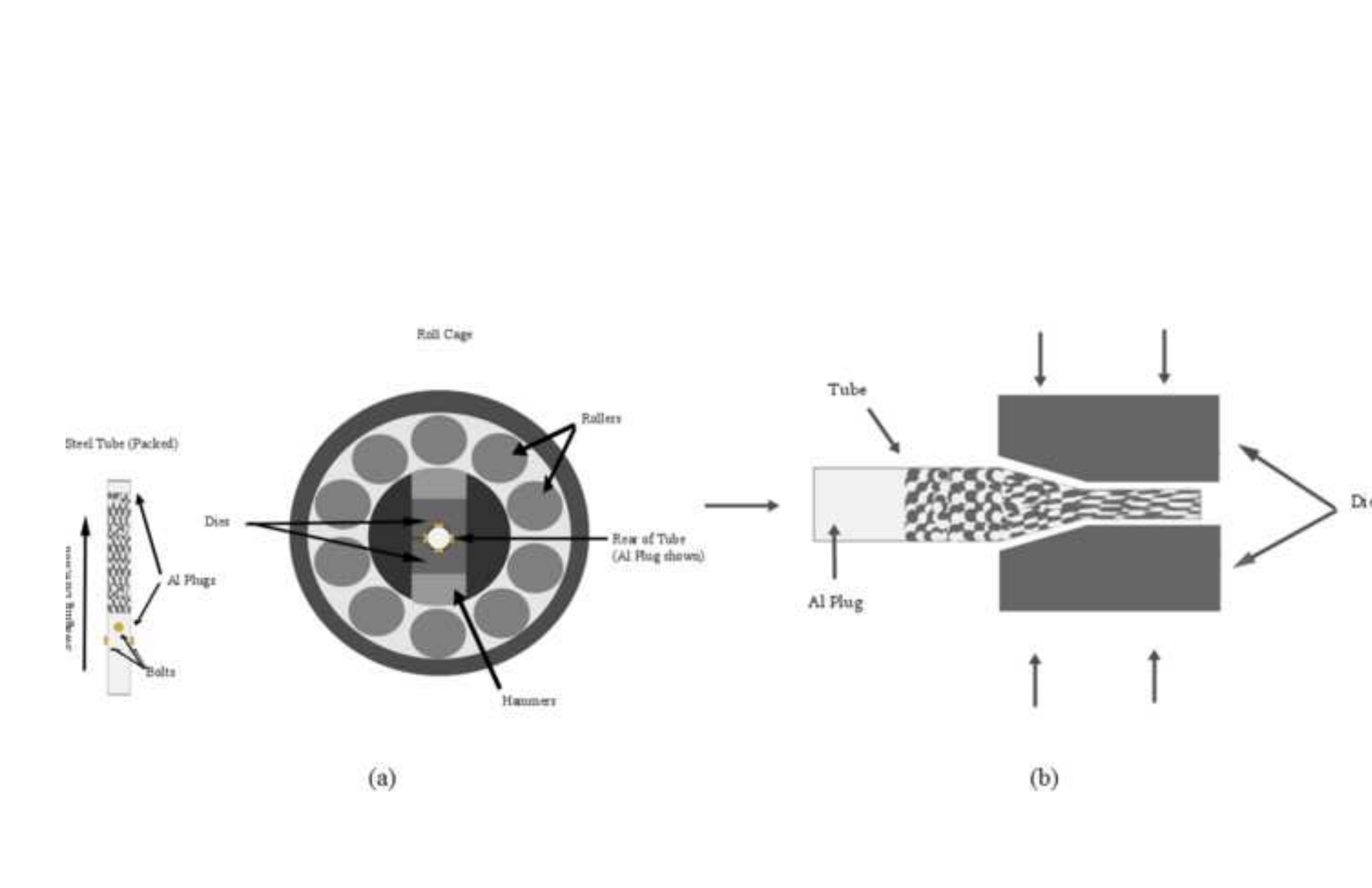

(b)

(b)

$12+\frac{1}{1}+\frac{1}{1}$

(b) .
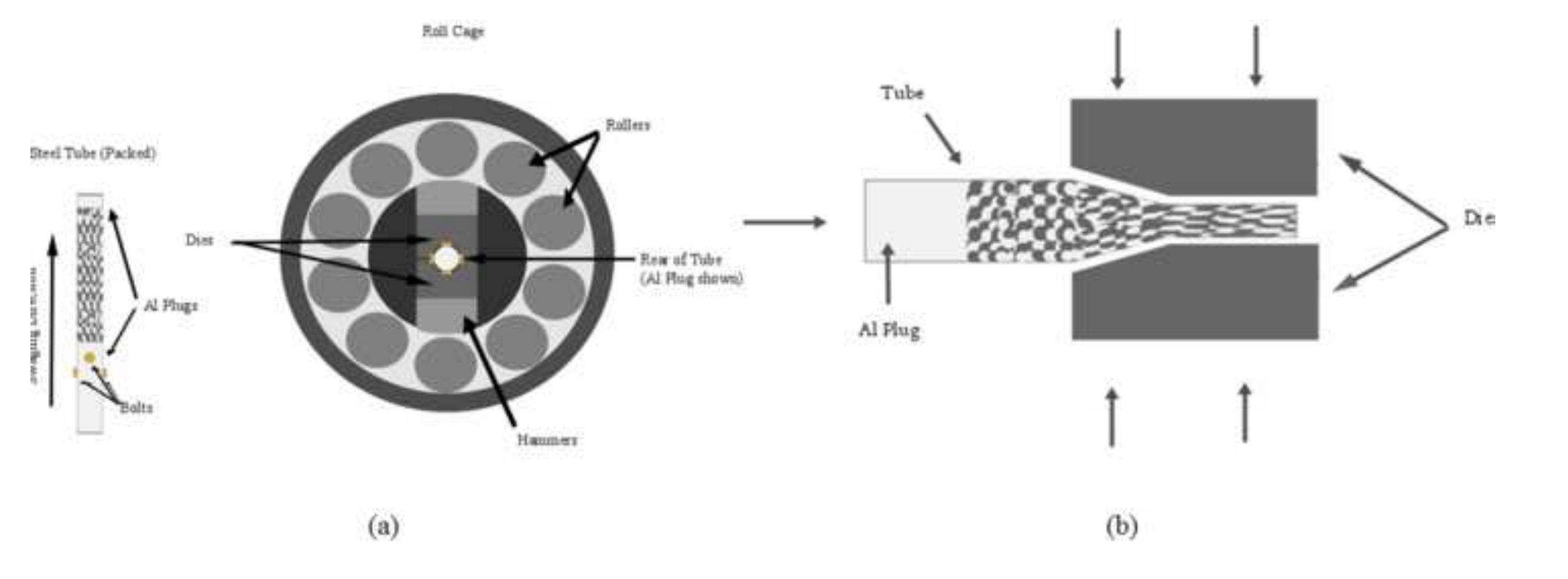

.

(b)

(2)

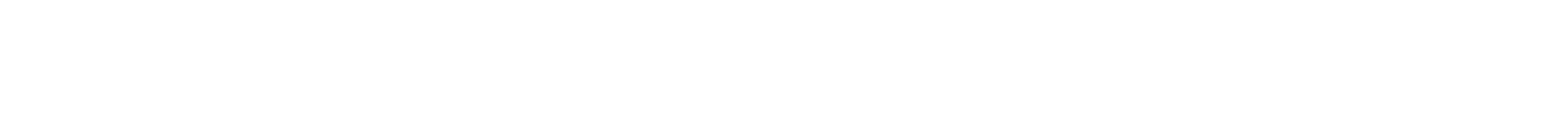

(a)

(a)

.

更

更

$\sqrt{2}-\frac{1}{1}>$ 


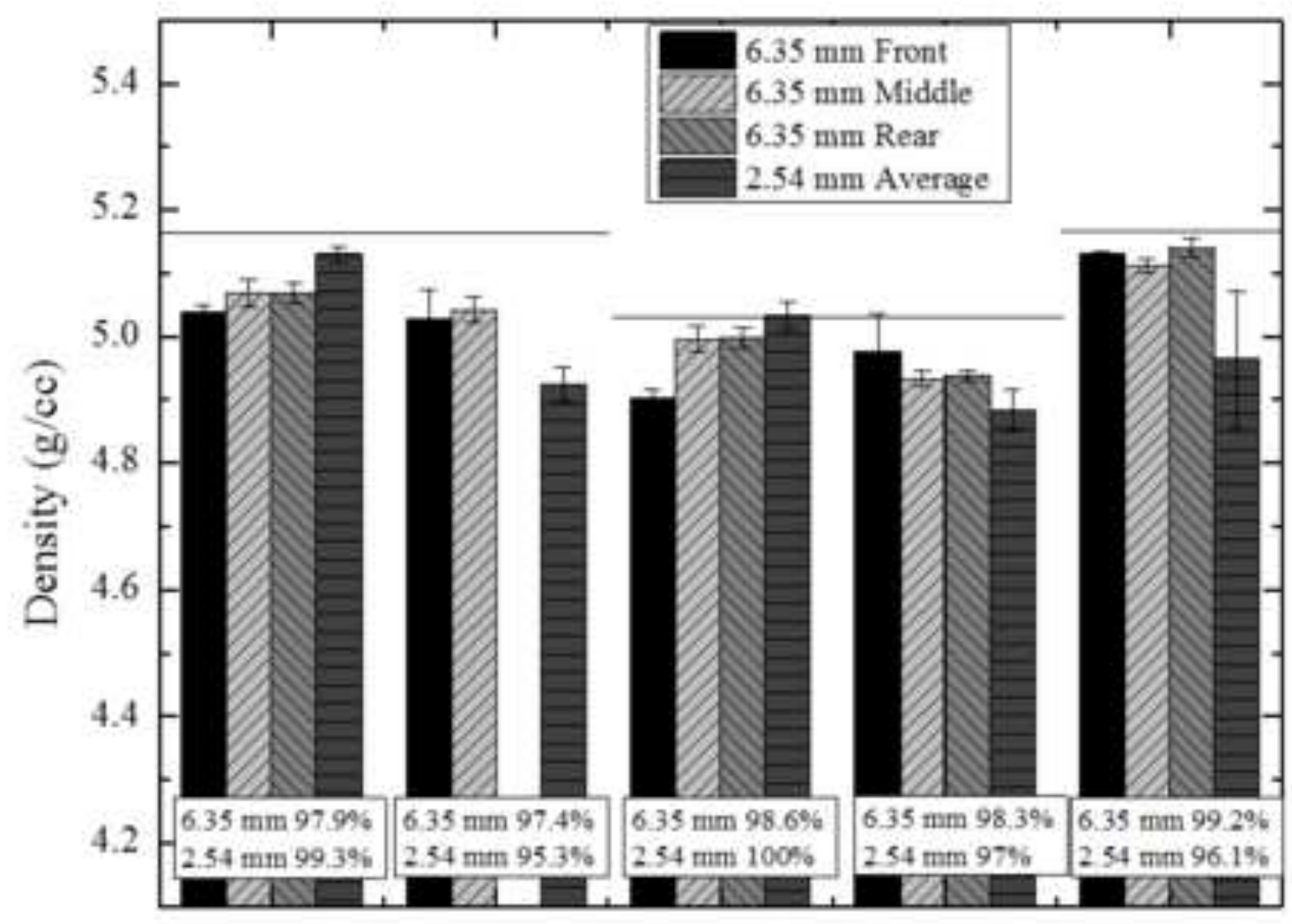

Al:NiP/P Al:NiP/F Al-Mg:NiP/P Al-Mg:NiP/F Al:NiLP 

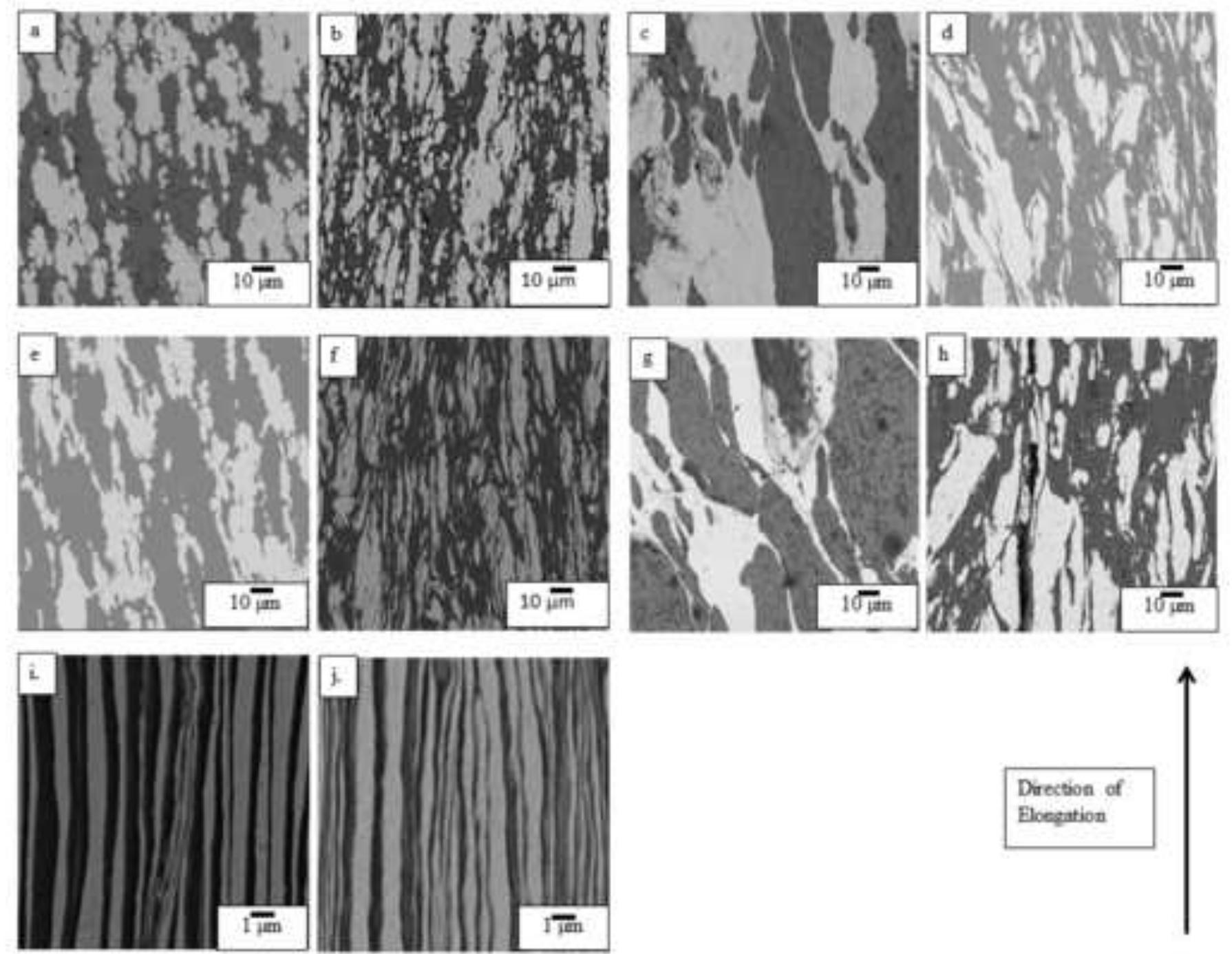

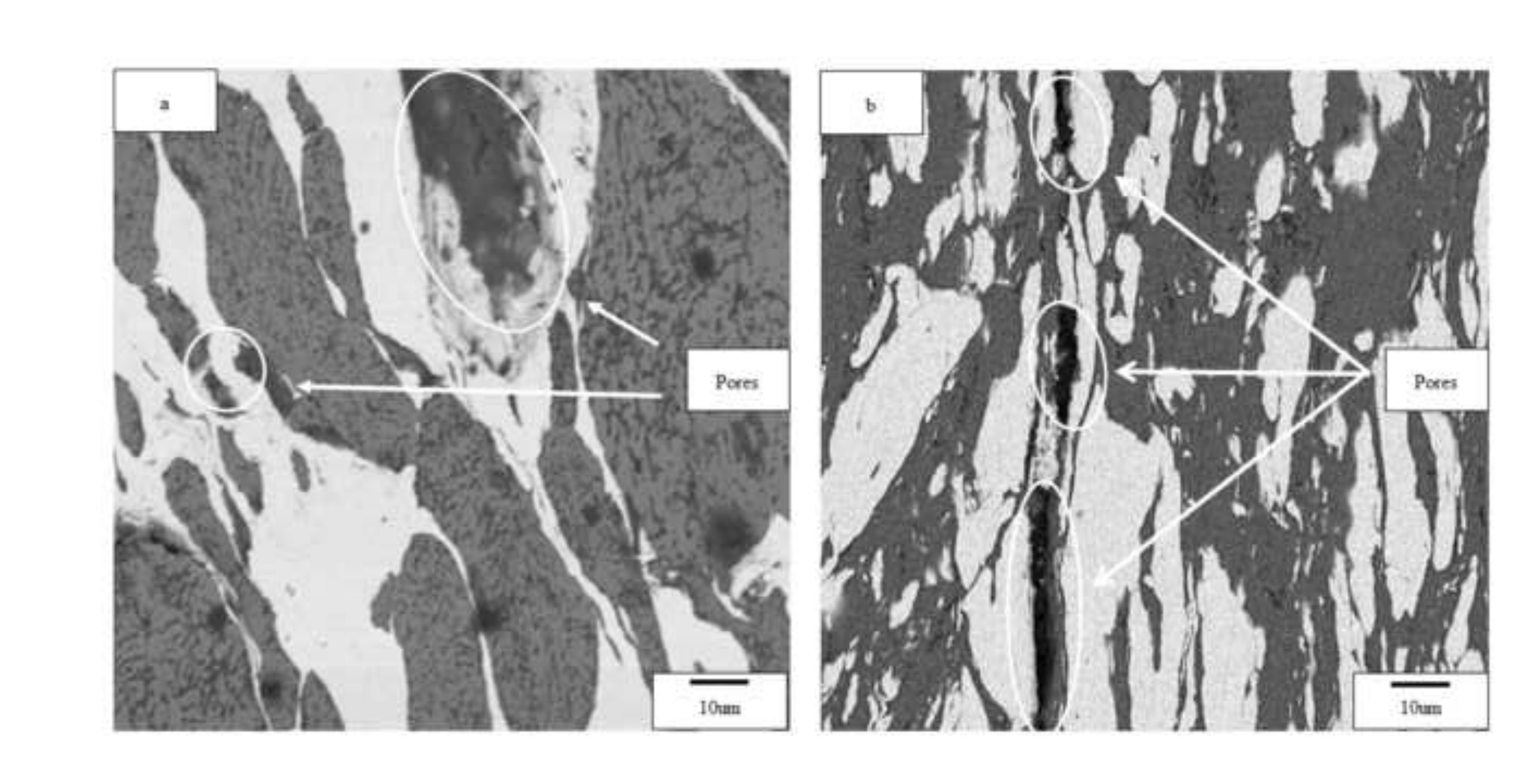

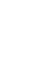

Figure 4
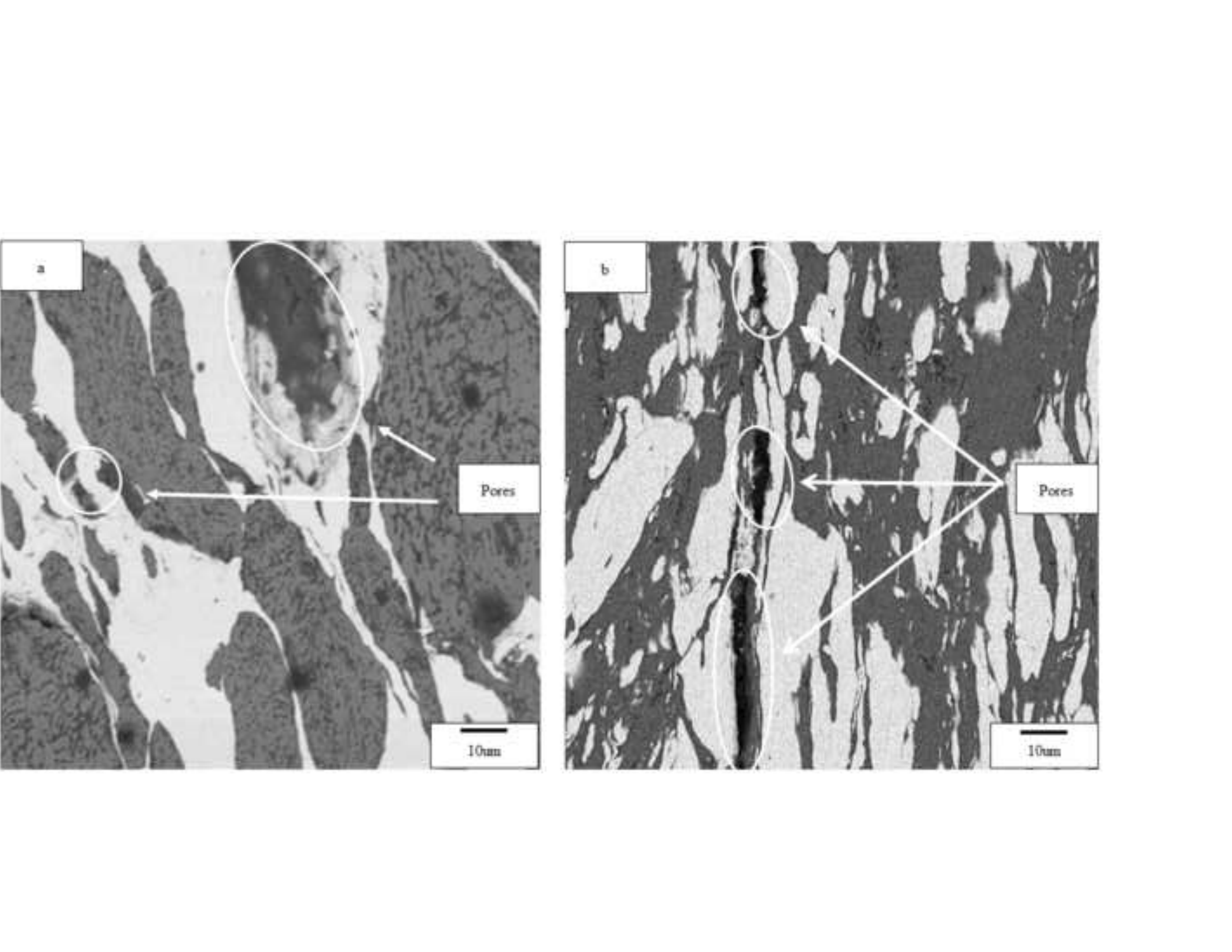

.

.
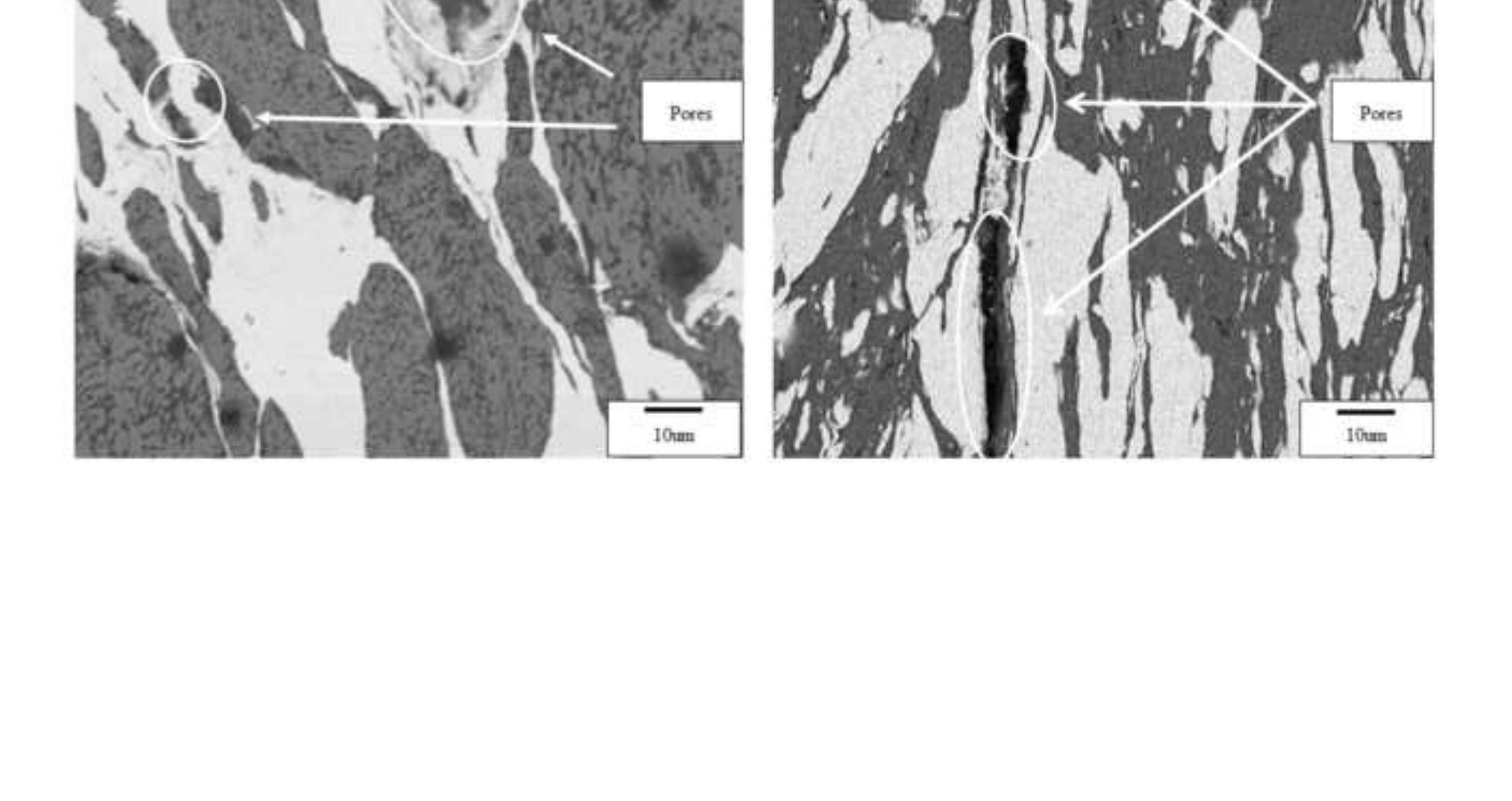


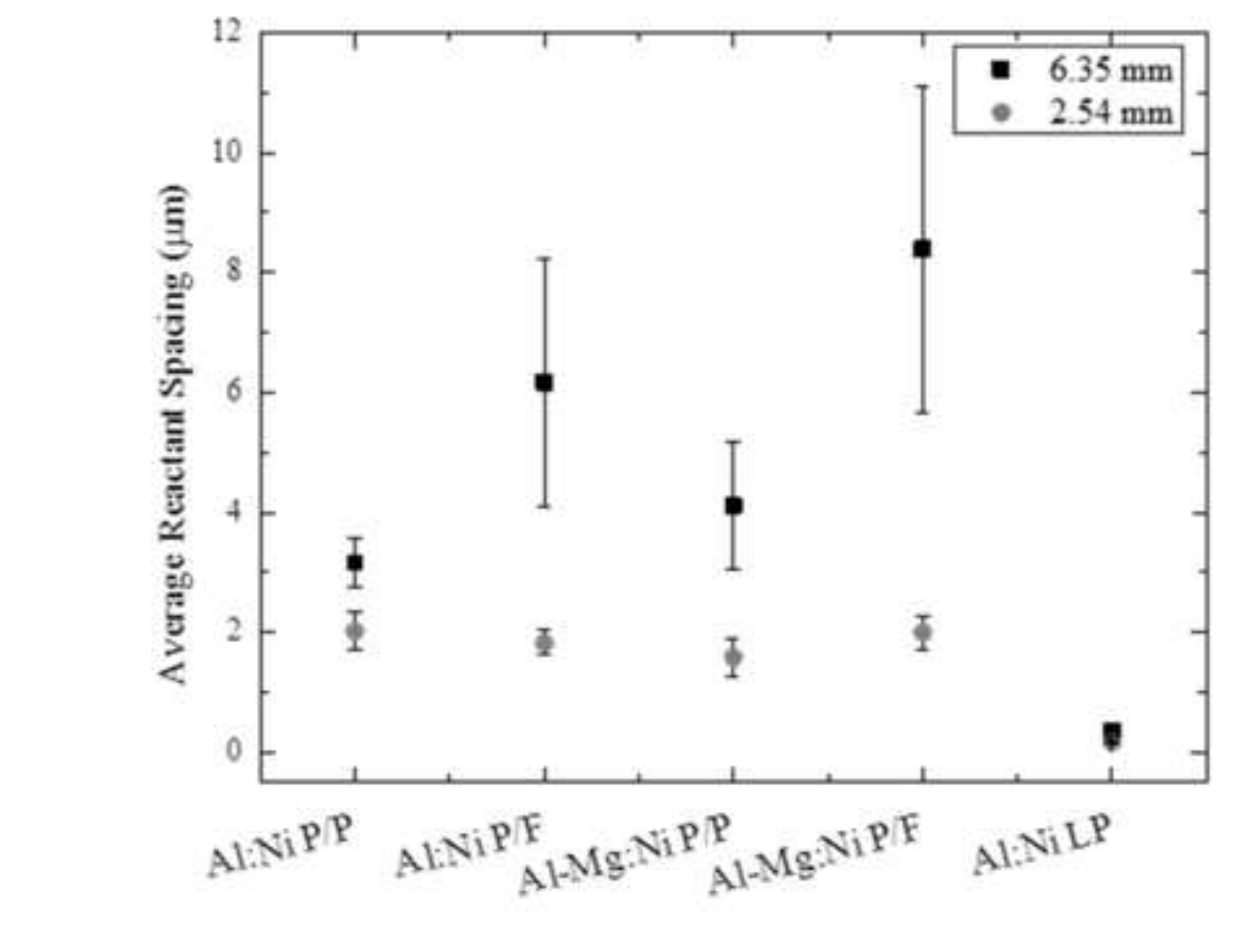

5

. 


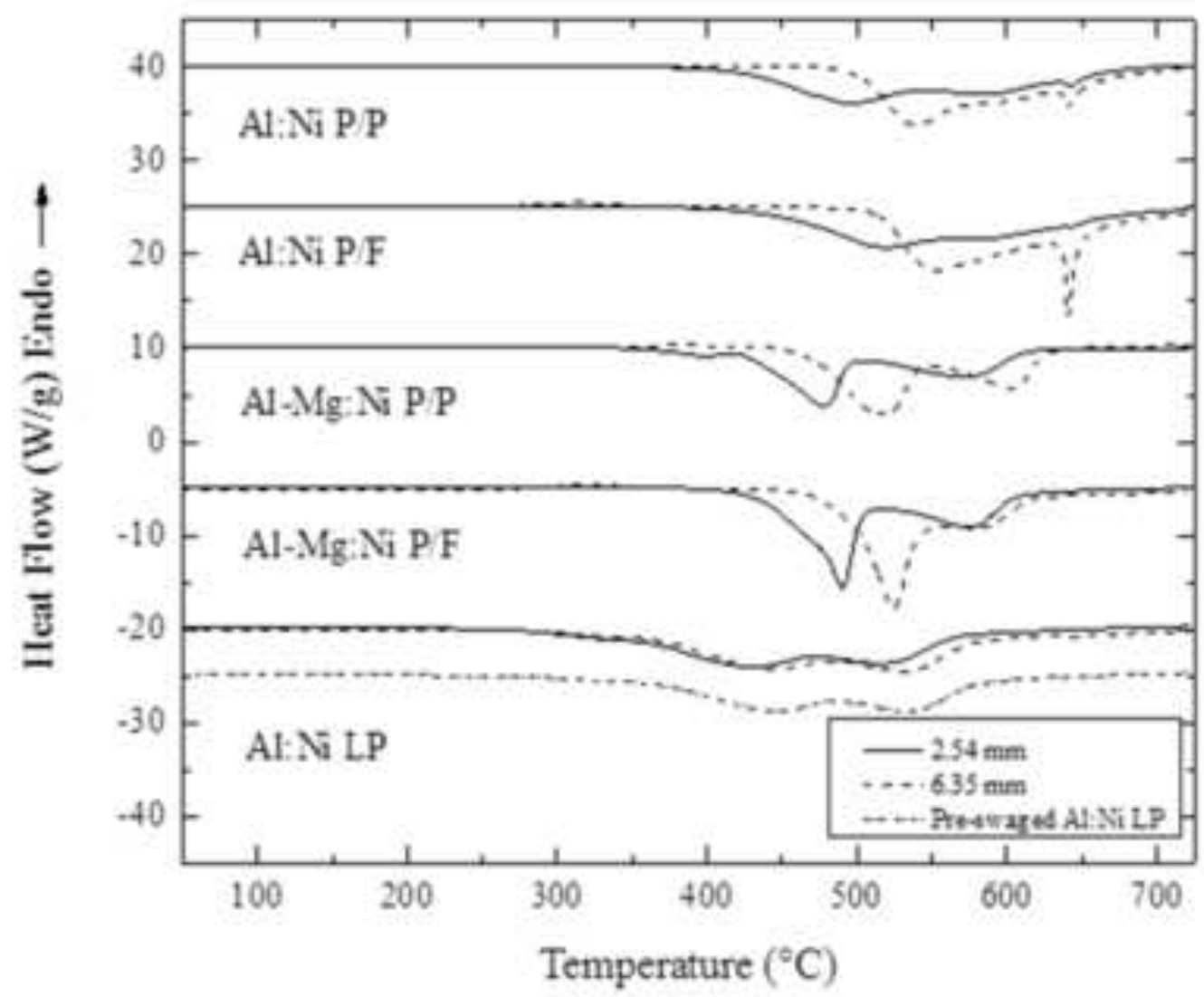

(a) 


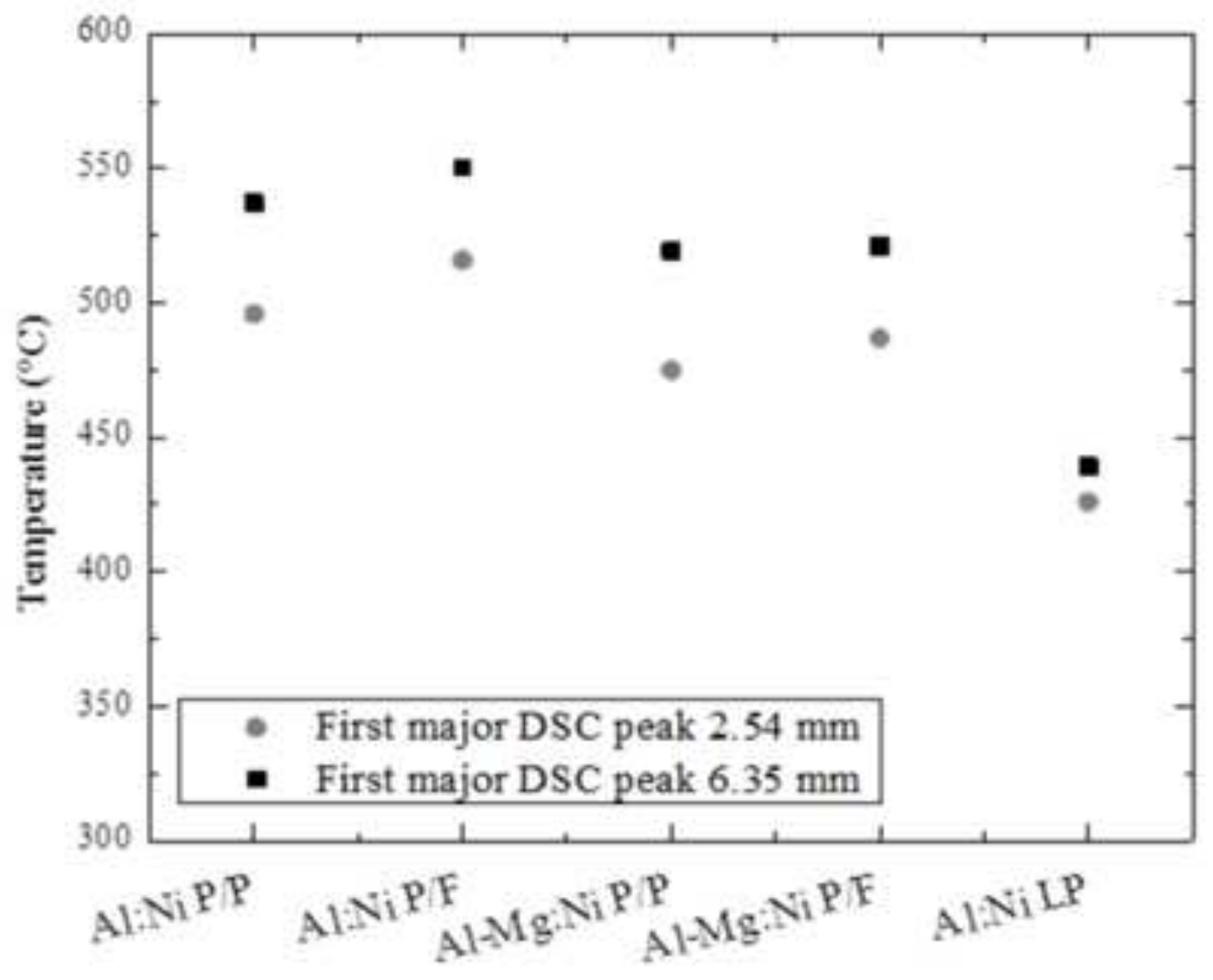

(b) 


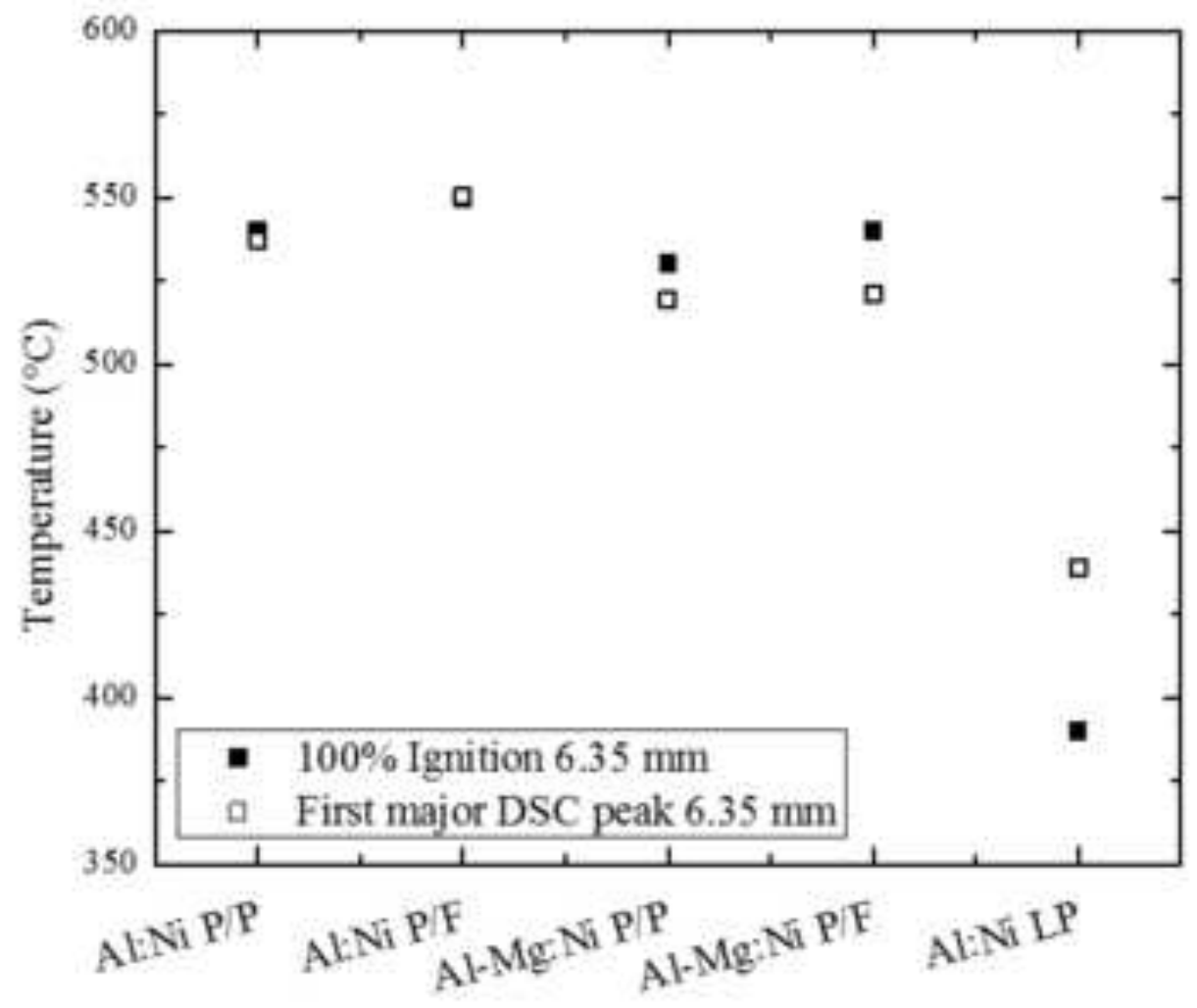

(b) 


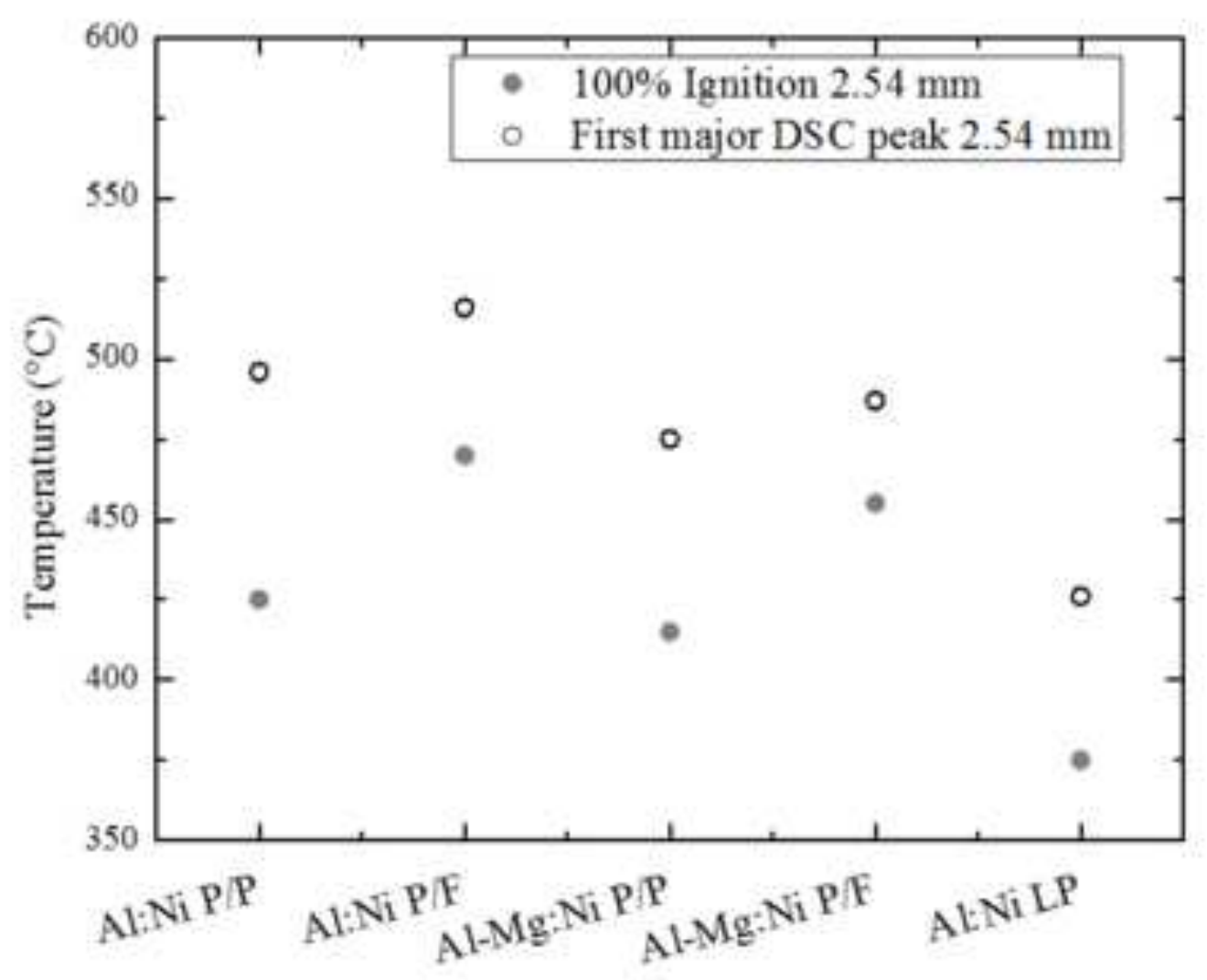

(c)

$$
\text { c) }
$$




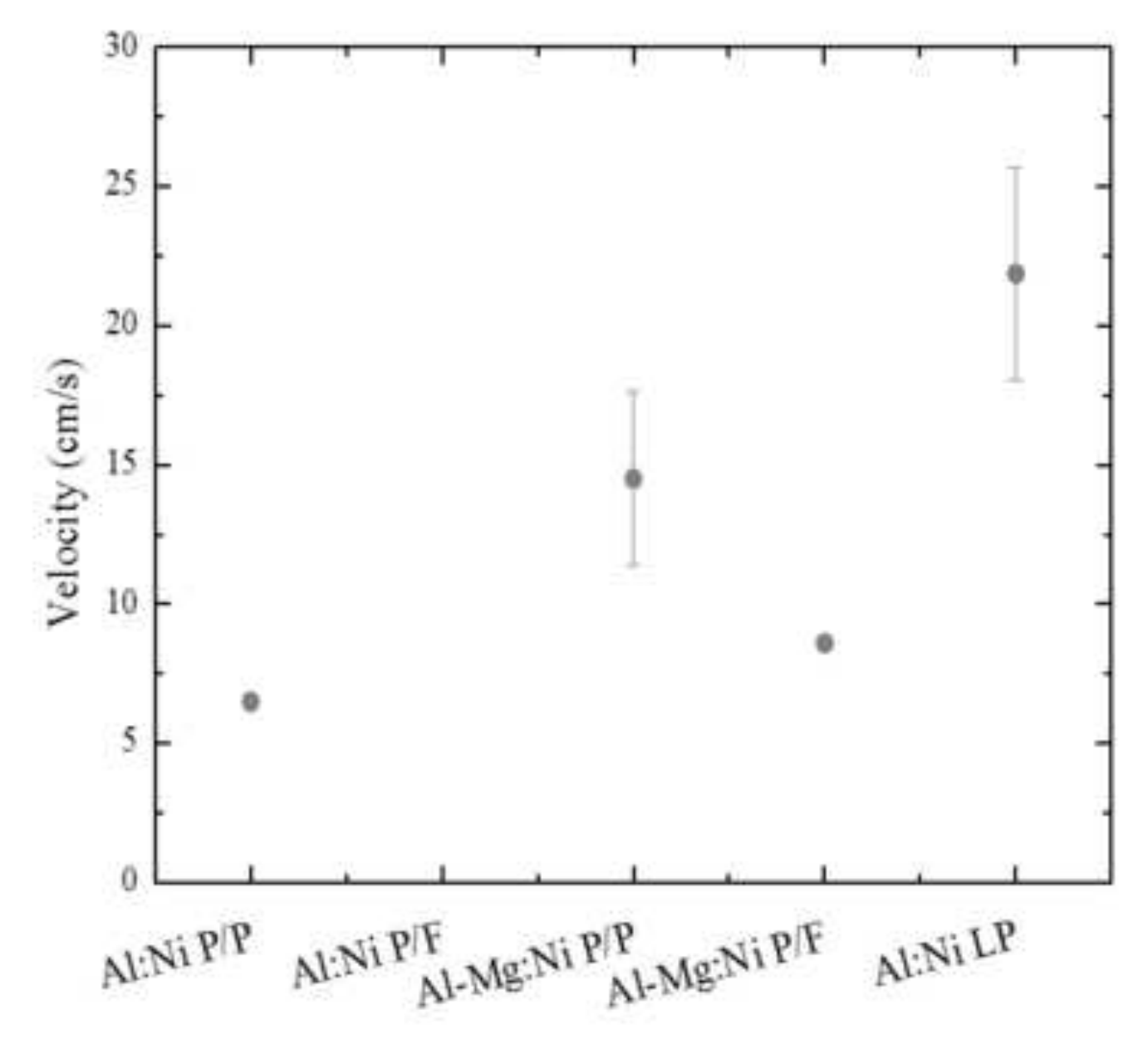




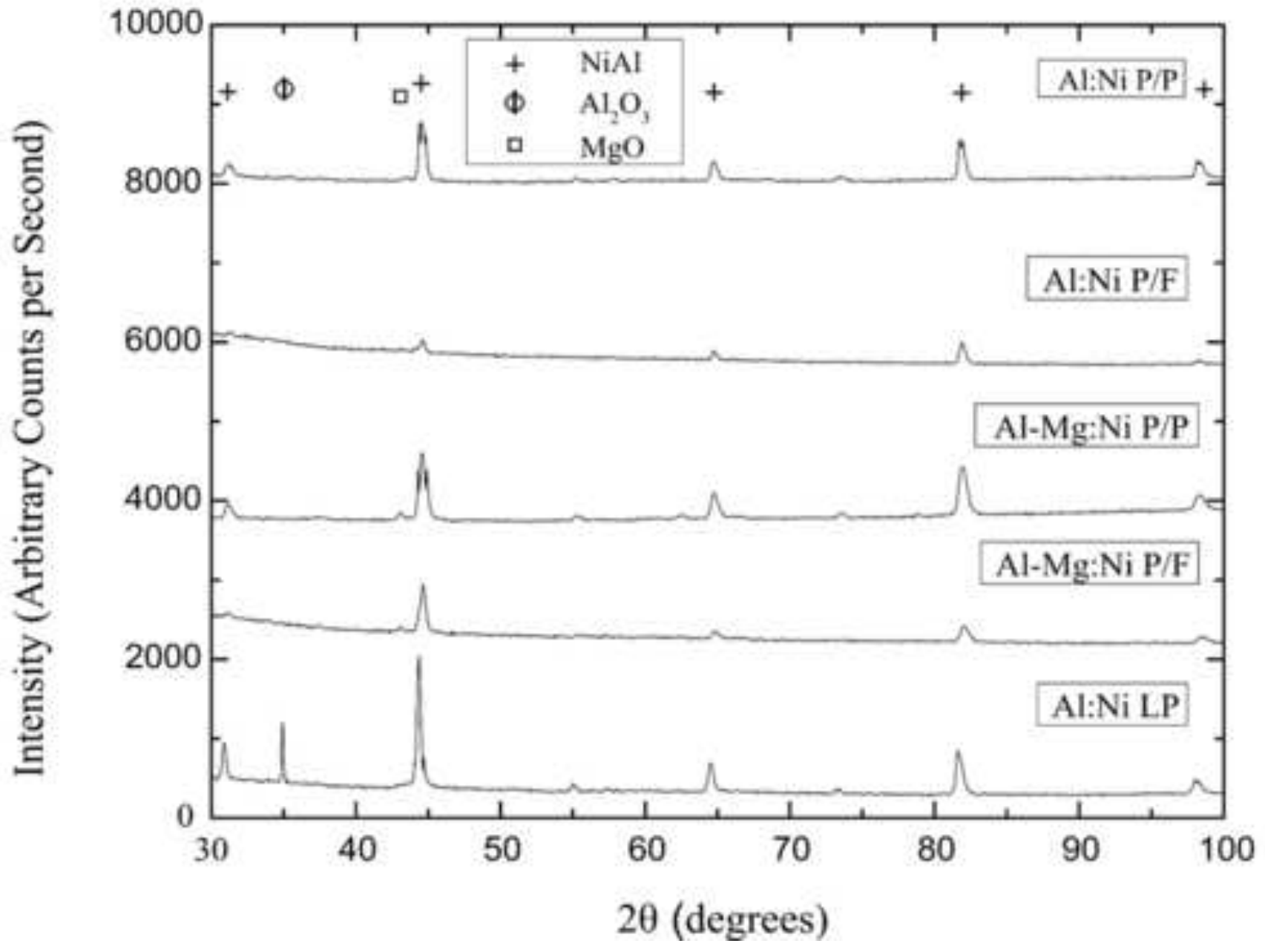

